\title{
Oxidative stress in prostate hyperplasia and carcinogenesis
}

\author{
Udensi K. Udensi and Paul B. Tchounwou*
}

\begin{abstract}
Prostatic hyperplasia (PH) is a common urologic disease that affects mostly elderly men. $\mathrm{PH}$ can be classified as benign prostatic hyperplasia (BPH), or prostate cancer (PCa) based on its severity. Oxidative stress (OS) is known to influence the activities of inflammatory mediators and other cellular processes involved in the initiation, promotion and progression of human neoplasms including prostate cancer. Scientific evidence also suggests that micronutrient supplementation may restore the antioxidant status and hence improve the clinical outcomes for patients with BPH and PCa. This review highlights the recent studies on prostate hyperplasia and carcinogenesis, and examines the role of OS on the molecular pathology of prostate cancer progression and treatment.
\end{abstract}

Keywords: Prostate cancer, Oxidative stress, Antioxidants, Cancer treatment

Abbreviations: 3aATA (8,24), 3a-acetyloxy-tir-8,24-dien-21-oic acid; 5-ARIs, 5a-Reductase inhibitors; 5-ARIs, 5a-reductase inhibitors; 8-EPI, 8-isoprostanes; 8-OHdG, 8-hydroxy-2'-deoxyguanosine; ADT, Androgen deprivation therapy; Akt, Alpha serine/threonine-protein kinase; AP1, Activator protein 1; AR, Androgen receptor; BHP, Benign prostatic hyperplasia; BRACA1, Breast cancer 1 gene; CDH13, Cadherin13; CML, Carboxy methyl lysine; COX2, Cyclooxygenase 2; CPNE2, Calcium-dependent membrane-binding protein; CPPS, Chronic pelvic pain syndrome; CRPC, Castration-resistant prostate cancer; CTA, Cancer/testis antigen; CXCR4, Chemokine receptor type 4; DNA, Deoxyribonucleic acid; DRE, Digital rectal examination; ELAC2, ElaC ribonuclease Z 2; ER, Estrogen receptor; FM, Fat mass; GLO1, Glyoxalase 1; GPX, Glutathione peroxidase; GST, Glutathione S-transferase; HFD, High-fat diet; HGIPN, High-grade intraepithelial neoplasia; HIC1, Hypermethylated in cancer 1 gene; HIF1A, Hypoxia inducible factor 1, alpha subunit; HMBA, 2-hydroxy-4-methoxy benzoic acid; HMOX1, Heme oxygenase 1; HO-1, Heme-oxygenase-1; HPC, Hereditary prostate cancer; IL6, Interleukin 6; iNOS, Inducible nitric oxide synthase; KLK3, Kallikrein-related peptidase 3; LOH, Loss of heterozygosity; LSMK2, Lemur tyrosine kinase 2; LUTS, Lower urinary tract symptoms; MDA, Malondialdehyde; MnSOD, Manganese superoxide dismutase; MSMB, Microseminoprotein, beta; mTOR, Mammalian target of rapamycin; NADPH, Nicotinamide adenine dinucleotide phosphate; NF-kB, Nuclear factor kappa B; NIH, National Institutes of Health; NIK, Nuclear factor kappa B inducing kinase; NOX, NADPH oxidase; Nrf2, Nuclear factor erythroid 2-related factor 2; OS, Oxidative stress; PAGE4, Prostate-associated gene 4; PCa, Prostate cancer; PEN, Phosphatase and tensin homolog; PH, Prostatic hyperplasia; PIA, Proliferative inflammatory atrophy; PIN, Prostate intraepithelial neoplasia; PKM2, Pyruvate kinase M2; PPARY, Peroxisome proliferator-activated receptor gamma; PSCA, Prostate stem cell antigen; PTGS, Prostaglandin-endoperoxide synthase 2; Rb, Retinoblastoma; RNASeq, Ribonucleic acid sequencing; RNS, Reactive nitrogen species; ROS, Reactive oxygen species; SDS 1, Stromal cell-derived factor 1; SNP, Single nucleotide polymorphism; SOD, Superoxide dismutase; SRD4A2, 3-oxo-5-alpha-steroid 4-dehydrogenase 2; STAMP2, Six transmembrane protein of prostate 2; STAT3, Signal transducer and activator of transcription 3; TBARS, Thiobarbituric acid reactive substances; TNF, Tumor necrotic factor; TRAMP, Transgenic adenocarcinoma of the mouse prostate; Trx1, Thioredoxin 1; TTG, Total thiol groups; VHL, Von Hippel-Lindau syndrome; WC, Waist circumference

\footnotetext{
* Correspondence: paul.b.tchounwou@jsums.edu

$\mathrm{NIH/NIMHD} \mathrm{RCMI}$ Center for Environmental Health, College of Science,

Engineering and Technology, Jackson State University, Jackson, MS 39217,

USA
}

(c) 2016 The Author(s). Open Access This article is distributed under the terms of the Creative Commons Attribution 4.0 International License (http://creativecommons.org/licenses/by/4.0/), which permits unrestricted use, distribution, and reproduction in any medium, provided you give appropriate credit to the original author(s) and the source, provide a link to the Creative Commons license, and indicate if changes were made. The Creative Commons Public Domain Dedication waiver (http://creativecommons.org/publicdomain/zero/1.0/) applies to the data made available in this article, unless otherwise stated. 


\section{Background}

Prostate cancer is the most common non-skin cancer affecting men and about 3 million men in the United States (U.S.) are currently living with the disease [1]. It is the second leading cause of cancer death after lung cancer among men in the U.S. [2]. Developing countries share a higher burden of $\mathrm{PCa}$ with higher incidence and death rates. It has been reported that $\mathrm{PCa}$ is a leading cause of cancer-related deaths among men in Nigeria [3].

$\mathrm{PCa}$ is classified as an adenocarcinoma and it is further classified based on its cell of origin. About $95 \%$ of prostate cancers develop in the acini of prostatic ducts. The remaining $5 \%$ are rare histopathologic types which include; small cell carcinoma, mucinous carcinoma, endometrioid cancer (prostatic ductal carcinoma), transitional cell cancer, squamous cell carcinoma, basal cell carcinoma, adenoid cystic carcinoma (basaloid), signetring cell carcinoma and neuroendocrine cancer [4]. Risk factors for PCa include; increasing age, family history, genetics, race (African-Americans are mostly affected), dietary factors. Some food nutrients have a level of protection against prostate cancer reduced fat intake, soy protein, lycopene, vitamin E, selenium [5]. Some plants such as Vernonia amygdalina have shown to have components which may complement the therapeutic effects of some established PCa drugs such as Paclitaxel [6].

Oxidative stress (OS) is considered to be one of the mechanisms that trigger the chain of reactions involved in the development and progression of prostatic hyperplasia $(\mathrm{PH})$. OS is a condition in the cellular environment which occurs when there is an imbalance between the production of reactive oxygen species (ROS) and the ability of biological systems to repair oxidative damage or neutralize the effects of reactive intermediates including peroxides and free radicals. Production of high levels of ROS causes a significant decrease in antioxidant defense mechanisms leading to protein, lipid and DNA damage and subsequent disruption of cellular functions and cell death but at lower levels induce subtle changes in intracellular signaling pathways $[7,8]$. The oxidative damage can be exacerbated by a decreased efficiency of antioxidant defense mechanisms [9]. Like many different cancer types, OS has been linked with benign prostatic hyperplasia $(\mathrm{BPH})$ and prostate cancer (PCa) development, progression and the response to therapy [10-14]. $\mathrm{OS}$ and $\mathrm{PCa}$ are both associated with increasing age because $\mathrm{PCa}$ is more prevalent in older men. Hence, it has been reported that age increases the prooxidantantioxidant balance toward a more oxidative state in many tissues [15].

Several mechanisms for prostate hyperplasia development have been suggested and these include; oxidative stress (OS) [10-14], inflammatory mediators [3, 16-20], hormones (especially androgens whose increase in physiologic level can cause increase in oxidative stress and alterations in intracellular glutathione levels and the activity of other detoxification enzymes required for the maintenance of the cellular prooxidant-antioxidant balance such as gamma-glutamyl transpeptidase) [15], enzymatic factors, dietary factors [21-23], inflammatory genes [17, 24] and Gleason score grading system (Fig. 1) which is used to evaluate the prognosis of $\mathrm{PCa}$ [12]. Reactive nitrogen species (RNS) and ROS are byproducts of normal cellular metabolism which impact on cell signaling. Increase in the levels of ROS and RNS induces oxidative stress, causing the cells to activate a variety of mechanisms that allow them to cope with these changes [25]. It is known that OS contributes to the initiation and progression of $\mathrm{PCa}$ by regulating molecules such as DNA, transcription factors, and cell cycle regulators [12]. Other studies have shown that antioxidants and other molecules that protect cells against OS play a role in the prevention of $\mathrm{PCa}$. The potential chemoprotective role of ROS regulators in the fight against $\mathrm{PCa}$ has been reported [26]. Chronic increases in ROS over time are known to induce somatic mutations and neoplastic transformation [27]. As shown in Fig. 2, several predisposing factors have been postulated to contribute to $\mathrm{PCa}$ initiation, promotion and progression. Age, race and family history play predominant roles however environmental factors such as chronic prostatitis, diet, medication and exposure radiation are associated with $\mathrm{PCa}$. Cellular dysfunction including aberrant signaling, genotoxicity, gene mutation, DNA damage, cell cycle arrest, apoptosis and mitochondrial mutation also affect the PCa carcinogenesis and metastasis.

This review highlights recent studies on the role of OS in prostatic hyperplasia initiation, promotion and progression. It also discusses its potential for treatment and offers more insight into the relationships between oxidative stress, redox homeostasis (antioxidants balancing the negative effect of free radicals), growth activation, and induction of molecular pathways in prostate tumorigenesis.

\section{Prostate cancer and enzymatic antioxidants}

$\mathrm{PCa}$ is characterized by an increase or decrease in blood levels of certain enzymes and antioxidants. One of such agents is malondialdehyde (MDA) which is a product of the peroxidation of polyunsaturated fatty acids and some esters and it is commonly used as an indicator of lipid peroxidation. Its determination is based on a non-invasive method and its level in blood is measured to determine oxidative stress status of the body. Increase of MDA level is associated with oxidative stress [10, 21, 28-31]. Oxidative stress could also be estimated through measuring the levels of erythrocyte MDA, erythrocyte activities of superoxide dismutase (CuZn-SOD), glutathione peroxidase (GPX), catalase (CAT), plasma nitrite/nitrate 


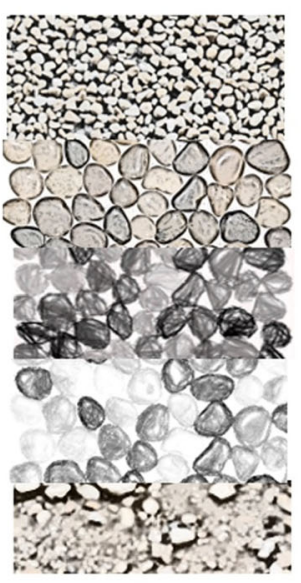

Small uniform glands

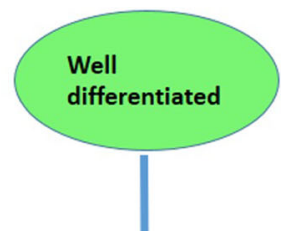

Increased spaces

between glands

Cells Infiltrated from

glands at margins

Irregular masses of neoplastic cells with few glands

Lack of glands

Fig. 1 Gleason's Pattern of Prostate Carcinogenesis: Gleason's score is the standard used to stage prostate cancer. It helps to determine the treatment strategy to be employed

$(\mathrm{NO}(2)(-) / \mathrm{NO}(3)(-))$, cGMP and 8-hydroxy-2'-deoxyguanosine $(8-\mathrm{OHdG})$ in plasma of prostate cancer patients. $\mathrm{PCa}$ is correlated with an imbalance in the oxidative stress/antioxidant status and an alteration of nitrosative status [31, 32].
The application of MDA in PCa diagnosis is growing and its measurement is now done in combination with prostate-specific antigen (PSA) which is a sensitive and generally accepted marker for prostatic hypertrophy and cancer. Increase in PSA is correlated with the severity of

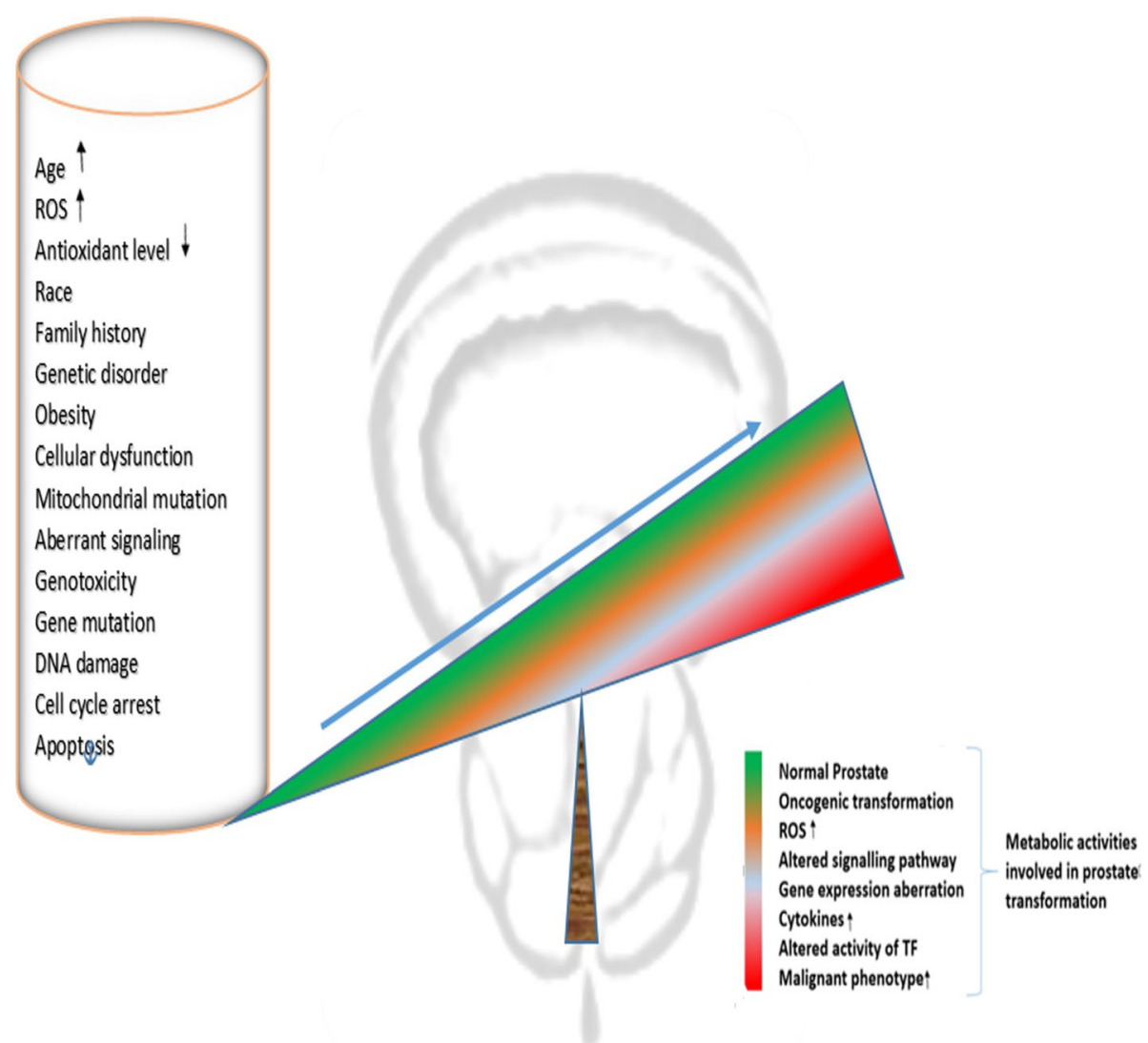

Fig. 2 Prostate Cancer and Predisposing Factors: This illustrates the relationship between oxidative stress, antioxidant agents and other predisposing factors such as age, sex, race, and family history in prostate cancer 
PCa but PSA is always performed with another marker such as MDA [21, 28, 33]. Manganese superoxide dismutase $(\mathrm{MnSOD})$ is under consideration as potential clinical marker to predict the progression of PCa [34]. Superoxide dismutase-3 (SOD3) is known to protect cell surface from oxidative stress. It has been reported that the expression of SOD3 is reduced in PCa tissue. Also, an inhibition of cell proliferation, migration, and invasion has been associated with SOD3 overexpression in PC-3 cell line [22]. Generally, $\mathrm{PCa}$ is accompanied with a decrease in serum level of anti-oxidants such as GPX, GSH-Px, SOD $[14,35]$, and an increase in concentrations of thiobarbituric acid reactive substances (TBARS) [36] and lipid peroxidation byproducts [11]. Thioredoxin 1 (Trx 1), is another enzyme which acts as a subcellular indicator of redox status in PCa and has demonstrated that both endogenous and exogenous antioxidants are involved in determining how PCa progresses. It can be correlated with the Gleason score. The level of Trx1 can be used to predict the stages of $\mathrm{PCa}$, the difference between malignant and benign tissue [37]. Nitric oxide generated by inducible nitric oxide synthase (iNOS) may be involved in prostate tumorigenesis, however the exact mechanism has not been elucidated, and warrants further studies [38].

\section{Prostate cancer and non-enzymatic antioxidants}

The idea that OS is involved in prostate tumorigenesis has been supported by the observed decrease in levels of non-enzymatic antioxidants, such as vitamins $C$ and $E$, in the plasma and erythrocytes of $\mathrm{PCa}$ patients compared to normal subjects [39, 40]. As an antioxidant, vitamin $\mathrm{E}$ scavenges lipid radicals and terminates oxidative chain reactions by interacting with the lipid peroxyl radical. This prevents further generation a new radical. However, there are contrary opinions about the role of vitamin $\mathrm{C}$ and vitamin $\mathrm{E}$ in PCa carcinogenesis. The effect of vitamin $C$ is still murky, in-vitro studies with cell line models show that vitamin $\mathrm{C}$ can fight against $\mathrm{PCa}$ [41] but in-vivo studies could not demonstrate vividly the same result. However, different forms of vitamin $\mathrm{E}$ are said to have different effects; alpha-tocopherol which scavenges singlet oxygen potentially increases the risk while gamma-tocopherol potentially decreases risk of developing PCa $[41,42]$. PCa patients also have lower levels of zinc $(\mathrm{Zn})$ [11]. The reduction in antioxidants in PCa patients suggests that micronutrient supplementation could be helpful in the prevention and management of the disease [14, 35, 43, 44]. Supplementation should be approached with caution as some micronutrients such as vitamin D may have a detrimental effect and increase the risk of $\mathrm{PCa}$ [45]. It has been reported that metastatic PCa patients have a higher Gleason score $(p<0.01)$ and more hormonal treatment, but lower concentrations of PSA $(p<0.05)$, alpha-tocopherol $(p<$ or $=0.05)$, retinol $(p<0.01)$, lutein $(p<0.05)$ and lycopene $(p<0.01)$, compared with patients having localized disease. Lower concentrations of carotenoids, in particular, lycopene reflect disease progression rather than the systemic inflammatory response in patients with $\mathrm{PCa}[21]$.

\section{Oxidative stress, prostate cancer and diet}

Diet plays a pivotal role in general body wellbeing. It not only boosts the immune system but also provides antioxidants that help the system to neutralize the negative effects of oxidative stress. Oxidative stress induced by chronic inflammation could be a cause, and dietary intake of antioxidants such as selenium may reduce the risk of developing prostate hyperplasia by reducing the deleterious effects of oxidative stress [46]. Selenium (Se) has been shown to prevent the development of PCa and it is highly accumulated around the prostate gland. Selenoproteins inhibit the transformation of normal prostate epithelium into neoplasm. A reduction in blood level of selenoproteins has been correlated with the risk of PCa [47]. Intake of some food rich in antioxidants can boost body's protection against disease. Pomegranate, a plant rich in antioxidants, has shown some anti-PCa promises as it slows prostate cancer xenograft growth and prolongs prostate-specific antigen (PSA) doubling times [48]. Extracts from Vernonia amygdalina has shown promises a supplementary drug to taxol-resistant prostate adenocarcinoma cells [6].

Oxidative stress and body composition contribute to the progression of PCa. High fat diet (HFD) has been identified as a risk factor for PCa because HFD induces oxidative stress and inflammation in the prostate gland. This stress triggers a cascade of activities within the gland culminating to hyperplasia. HFD induces significant increases in the levels of pro-inflammatory cytokines and gene products. It is also speculated that HFD can activate signaling pathways. For example, the signal transducer and activator of transcription (STAT)-3 and nuclear factor-kappa B (NF-kB) which are transcription factors required for regulating genes involved in proliferation, survival, angiogenesis, invasion and inflammation [17]. Measuring body composition can be used to predict risk to developing PCa. This phenomenon has been by using a combination of the measurement of glutathione, fat mass (FM) and waist circumference (WC) to predict the risk of $\mathrm{PCa}$ [13]. A study has suggested that dietary fat could encourage increase in proliferation of prostate intraepithelial neoplasia (PIN) and suppression of glutathione peroxidase 3 (GPx3) expression [22]. PIN stage is crucial in prostate carcinogenesis as shown in Fig. 3. Cells have gone through neoplastic changes and have become carcinogenic and ready to invade other cells. High-grade prostatic intraepithelial neoplasia has a high predictive value and is considered as a reliable 


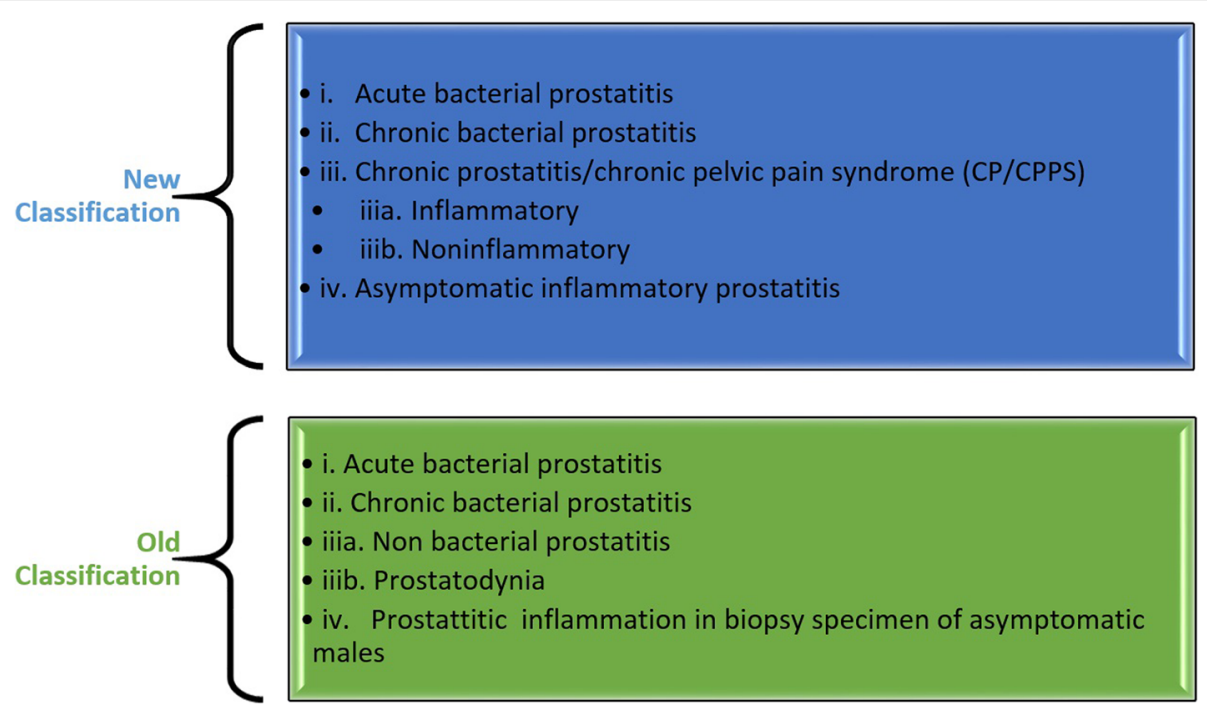

Fig. 3 The NIH Consensus Classification of Prostatitis Syndromes [54, 56, 57, 150]

indicator of pre-invasive stage of adenocarcinoma [49]. An antioxidant, 2-hydroxy-4-methoxy benzoic acid (HMBA) has protective effects in rats against testosterone induced $\mathrm{BPH}$ and this may have a similar effect on PCa [29].

\section{Symptoms and diagnosis of $\mathrm{PCa}$}

$\mathrm{PCa}$ presents different clinical signs and symptoms which range from asymptomatic, inactive, slow-growing tumors to aggressive, fast-growing tumors with lethal progression. Symptoms of PCa may include; problems passing urine, such as pain, difficulty starting or stopping the stream, or dribbling, low back pain and pain with ejaculation. The rate at which cancer grows and the difference in its appearance from surrounding tissue helps determine the stage [50]. Like most epithelial cancers the keys to survival and treatment are early diagnosis and identification of PCa type. Androgens and androgen receptor (AR) are required by both normal prostate and prostate cancer cells for growth and survival [51]. Androgen receptor mutations are observed in late stage prostate cancer. Androgen ablation and antiandrogen therapy cause the cancer to regress. Androgen-independent prostate cancer which does not respond to anti-androgen therapy has been observed in some patients especially in patients whose cancer was not cured by surgery. Overexpression of Caveolin-1 occurs in about a quarter of human prostate cancers and is thought to induce androgen sensitivity in androgen-insensitive prostate cancer cells [52]. However, a recent study has suggested that Metformin, commonly used for type 2 diabetes, may have promising therapeutic effects on both androgen-dependent and androgen-independent PCa [40]. Most facilities use diagnostic test kits that measure the level of prostate-specific antigen (PSA) in serum of patients to detect early stages of PCa. If the PSA level is high, the patient is subjected to more invasive biopsy to ascertain the histopathological grading. A Gleason scoring is used to classify the extent of differentiation of tumors as well as staging (determination of the status of the primary tumors, with or without lymph node involvement) [53]. The categories of prostatitis are shown in Fig. 4.

Prostatitis are classified in to four categories by Meares and Stamey [54], but this was later replaced by the U.S. National Institutes of Health (NIH) classification scheme: Category I-acute bacterial prostatitis; Category II-chronic bacterial prostatitis; Category III-chronic abacterial prostatitis/chronic pelvic pain syndrome [CPPS]) [55]. Category III was further subdivided into IIIa-inflammatory CPPS, and IIIb-non-inflammatory CPPS. Category IV encompasses asymptomatic inflammatory prostatitis. Prostate specimens often reveal evidence of category IV prostatitis after a biopsy [56, 57]. Differential diagnosis of PCa involves differentiating symptoms of PCA; those caused by acute cystitis, benign prostatic hyperplasia $(\mathrm{BPH})$, urinary tract stones, bladder cancer, and rectal tumor and other factors that cause strictures. Other factors that cause urinary symptoms similar to $\mathrm{PCa}$ include urinary tract infections (UTI), diuretics, spinal injury, autonomic neuropathy, prostatic abscess, enterovesical fistula, and foreign body within the urinary tract. Most of these conditions like PCa cause urinary obstruction, urine retention, lack of urine, urinary dribbling, urinary urgency, urination pain, and weak urination [58].

The diagnostic methods for PCa include assays based on the evaluation of oxidative stress. The assays are further categorized into: (i) assays that measure the concentrations of oxidation products of lipids, proteins and DNA, as well as the concentrations of antioxidants, (ii) 


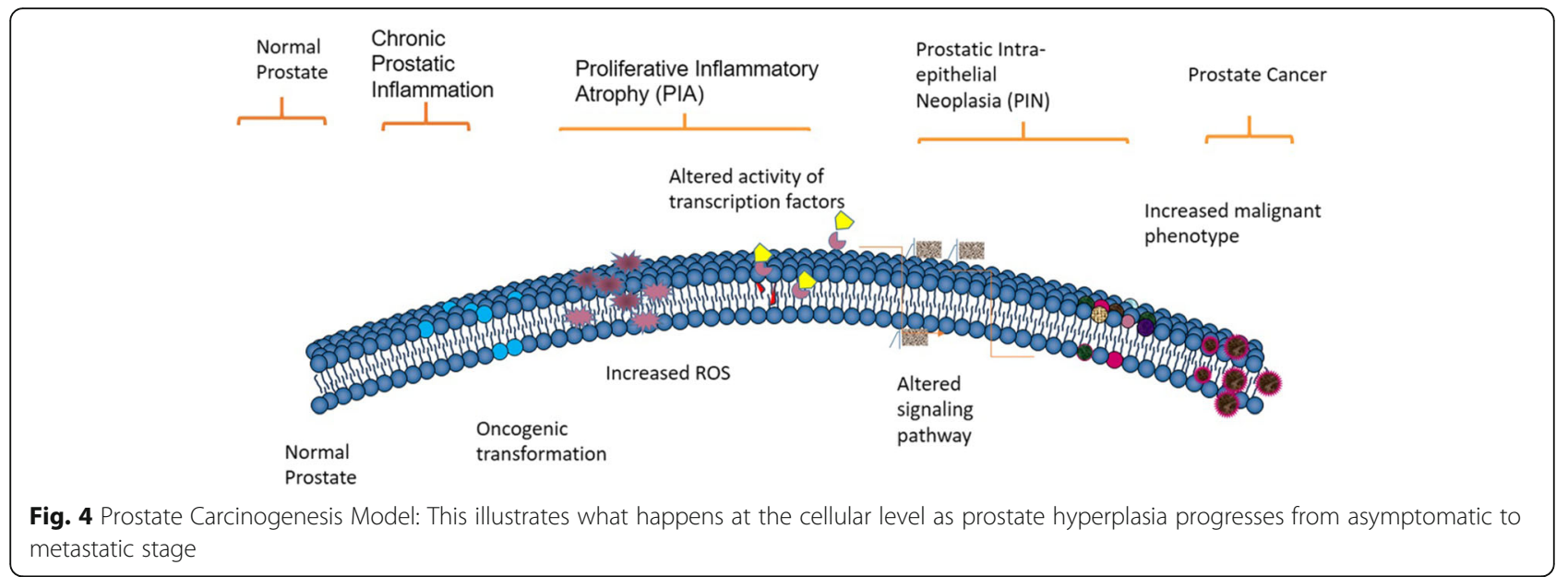

assays that determine the oxidative and reductive capacity of biological fluids, and (iii) assays that measure the ex vivo susceptibility of lipids to oxidation when exposed to a source of free radicals [59]. Some of the oxidative biomarkers that are frequently measured are; lipid peroxidation, total antioxidant capacity and total thiol molecules [60]. Table 1 presents a list of laboratory tests that are used to diagnose and monitor the progress of $\mathrm{PCa}$.

These biomarkers can be assayed in different body specimens such as the whole blood, plasma, serum, urine, and tissue biopsies. Biomarkers discussed in this review are limited to those that are linked to oxidative stress. Recently, F2-isoprostanes, a group of prostaglandin F(2)-like compounds derived from the non-enzymatic oxidation of arachidonic acid have been used as markers of lipid oxidation and the results showed an accurate assessment of oxidative stress both in vitro and in vivo in urine, blood and tissue biopsies [61]. Other biomarkers of oxidative stress are plasma fluorescent oxidation products which detect global oxidation, and carboxy methyl lysine $(\mathrm{CML})$ which

Table 1 Laboratory Tests Used to Diagnose and Monitor PCa Biomarkers

\begin{tabular}{|c|c|c|c|c|}
\hline Test & Specimen & Factors measured & Method & Reference \\
\hline Oxidative stress & Blood & $\begin{array}{l}\text { Activity changes of superoxide-dismutase } \\
(\mathrm{SOD}) \text {, catalase (CAT), ceruloplasmin (Cp), } \\
\text { tripeptide glutathione (GSH), glutathione- } \\
\text { peroxidase (GSH-Px), and glutathione- } \\
\text { reductase (GR) }\end{array}$ & Spectrophotometry & {$[11,12,32]$} \\
\hline Oxidative stress & prostate tissue & Thioredoxin 1 ( $\operatorname{Tr} \times 1)$ & Spectrophotometry & {$[37]$} \\
\hline Oxidative stress & Tissue & Inducible NOS (iNOS or NOS-2) & $\begin{array}{l}\text { Immunohistochemistry and } \\
\text { reverse transcriptase-polymerase } \\
\text { chain reaction (RT-PCR) }\end{array}$ & [152] \\
\hline Oxidative stress & Blood & $\begin{array}{l}\text { Plasma oxidized low-density lipoprotein, } \\
\text { peroxides, and total equivalent antioxidant } \\
\text { capacity (TEAC) }\end{array}$ & Spectrophotometer & [32] \\
\hline Global oxidation & Blood & plasma fluorescent oxidation products & Spectrophotometry & [40] \\
\hline Oxidative stress & Blood & $\begin{array}{l}\text { carboxymethyllysine }(\mathrm{CML}) \text {, advanced } \\
\text { glycation end products (AGE) }\end{array}$ & Spectrophotometry & [40] \\
\hline Oxidative stress & $\begin{array}{l}\text { Prostatebiopsy } \\
\text { (needle biopsy) }\end{array}$ & Total thiol groups (TTG) level & $\begin{array}{l}\text { Spectrophotometry (2 thionitrobenzoic } \\
\text { acid (DTNB)) }\end{array}$ & {$[13,153]$} \\
\hline Lymphocyte DNA damage & Blood & lymphocyte DNA damage & $\begin{array}{l}\text { single cell alkaline gel electrophoresis, } \\
\text { tail length migration }\end{array}$ & [15] \\
\hline Lipid peroxidation & Plasma & $\begin{array}{l}\text { Thiobarbituric acid reactive substances } \\
\text { (TBARS), serum protein carbonylation }\end{array}$ & $\begin{array}{l}\text { Spectrophotometry; Thiobarbituric acid } \\
\text { (TBA), concentrations of TBA- MDA adduct }\end{array}$ & {$[12,36,154]$} \\
\hline Lipid oxidation & Urine, blood, tissues & F2-isoprostanes & $\begin{array}{l}\text { Gas/liquid chromatography-mass } \\
\text { spectrometry, mass spectrometry, } \\
\text { immunological methods }\end{array}$ & {$[40,61,155]$} \\
\hline Body composition & Air & $\begin{array}{l}\text { Volume of air the body displaced inside } \\
\text { an enclosed chamber (plethysmograph) }\end{array}$ & Air plethysmography (BOD POD) & {$[13,156]$} \\
\hline
\end{tabular}


detects advanced glycation end products. Higher levels of plasma CML signify increased risk of prostate cancer [40]. Lipid peroxidation contribute to cellular oxidative stress and cell death. This draws attention to the cellular activities that involve the thiol groups. The level of total thiol groups (TTG) has been associated with aging and progression of PCa. A comparison of the levels of TTG between $\mathrm{BPH}$ and PCa patients has shown that aging influences a progressive reduction of TTG in BPH patients, while in $\mathrm{PCa}$ patients the glutathione concentrations are significantly lower [13]. The determination of the level of 8-isoprostanes (8-EPI) in urine using competitive enzyme-linked immunoassay gives an idea of the oxidative stress status and the stage of the hyperplasia (NIH categories IIIa, IIIb, and IV) [62]. The new phase of diagnosis is moving towards the application of genetics and molecular techniques such as genetic linkage studies which is used to study the expression patterns of ncRNA transcription [63].

\section{Prostate cancer and benign prostatic hyperplasia (BPH)}

These two forms of prostatic hyperplasia are leading cause of urologic problems in older men. Although they can co-exist in an individual, there is no evidence that $\mathrm{BPH}$ is a precursor nor risk factor of PCa. There is no evidence that $\mathrm{BPH}$ can transform into PCa. However, both conditions share certain attributes in common. They are hormone and age dependent. Risk increases with age, and they are associated with certain forms of hyperplasia [64, 65]. They present similar symptoms and for accurate diagnosis $\mathrm{PCa}$ has to be differentiated from $\mathrm{BPH}$. Both $\mathrm{PCa}$ and $\mathrm{BPH}$ can cause lower urinary tract symptoms (LUTS). Additional tests and examinations are performed to differentiate LUTS caused by PCA and LUTS caused by BPH. For instance, PSA is performed in asymptomatic patients, while prostate biopsy is done on LUTS patients. Procedures such as bone pain are performed on patients with symptoms of metastasis. Evaluating the size of the prostate through digital rectal examination (DRE) is essential in the management of $\mathrm{BPH}$. A combination of DRE and PSA testing can be used to differentiate clinically between $\mathrm{PCa}$ and $\mathrm{BPH}$. The presence of a nodular abnormality puts the probability of diagnosing $\mathrm{PCa}$ on biopsy at $50 \%$. Blood level of PSA is no longer used alone for PCa diagnosis. It is now recommended to confirm increases in serum PSA levels with histology tests. Clinically, PCa could be ruled out if PSA and DRE density are normal [64]. Oxidative stress influences the pathophysiology of both $\mathrm{PCa}$ and $\mathrm{BPH}$. For instance, antioxidant defense system is decreased in the elderly patients with $\mathrm{PCa}$ and $\mathrm{BPH}$ [66]. Also, systemic metabolic stress occurs in glucose and fatty acid metabolism in $\mathrm{BPH}$ and PCa [67]. However, their response to therapeutics agents differs. And some drugs used in the treatment of BPH have been suspected to worsen the prognosis of PCa. An example is $5 \alpha-$ Reductase inhibitors (5-ARIs) which is the common drug of choice for BPH. It is suspected that 5-ARIs can trigger or increase the risk of developing high-grade prostate cancer. Studies could not associate 5-ARIs use with an increased risk of $\mathrm{PCa}[37,68]$. Rather in their review, Hamilton and Parsons suggested that 5-ARIs has protective potential and could reduce the risk of prostate cancer in some men [69].

\section{Prostate cancer, oxidative stress, and age}

There is a strong connection between age, OS, and PCA. PCA is predominant among older men and this makes age and family history the strongest predictors of prostate cancer risk. PCa is mostly seen in older men and Black/African Americans are disproportionately affected [20]. The risk of developing PCa increases exponentially with age [15]. For instance, only 1 in 10,000 under age 40 will be diagnosed, the rate goes up to 1 in 38 for ages 40 to 59 , and 1 in 14 for ages 60 to 69. Most PCa are diagnosed in men 50 years of age and older [1]. But the age of diagnosis is earlier among Black/African Americans and they are about four times more likely to die from PCa than White men [20,70]. On the other hand, according to the free radical theory of aging, oxidative stress is blamed for aging because of the negative impact the excessive free radicals or reactive oxygen species (ROS) have on the cells [71]. Also, antioxidant defense system is decreased in the elderly patients with $\mathrm{PCa}$ [66]. ROS and age are predominant factors in $\mathrm{PCa}$ and other aging-related diseases, such as, diabetes, atherosclerosis and degenerative diseases like Parkinson's and Alzheimer's. This is because older cells seem to be more susceptible to intracellular conditions that produce excess ROS which trigger and accelerate tumorigenesis [72]. It has been reported that age increases the prooxidant-antioxidant balance toward a more oxidative state in many tissues [15].

\section{Prostate cancer and non-coding RNA (ncRNAs)}

The interest in getting a better understanding of the molecular mechanisms involved in $\mathrm{PCa}$ pathogenesis and prognosis has led to exploring the role of non-coding RNA (ncRNAs). Only about $2 \%$ of human genome are protein-coding sequences while the remaining $98 \%$ are noncoding sequences that can be transcribed in ncRNAs. ncRNAs depending on the size are further grouped into long noncoding RNAs (lncRNAs) and small ncRNAs. Small ncRNAs include microRNAs (miRNAs), piwi-interacting RNAs (piRNAs), ribosomal RNAs (rRNAs), small Cajal body-specific RNAs (scaRNAs), small interfering RNAs (siRNAs), small nuclear RNAs (snRNAs), small nucleolar RNAs (snRNAs) and transfer 
RNAs (tRNAs). However, miRNAs can also be derived from lncRNAs and snoRNAs [63]. Previously, no functions were apportioned to ncRNAs since they are nonprotein-coding RNA species of the transcriptome. Recent studies have revealed that they play special roles in the tumorigenic processes by acting sometimes as oncogenic and tumor suppressor genes. Some perform similar functions as the house keeping genes being involved in mRNA processing and protein transcription [63]. Some ncRNAs perform regulatory functions such as pre- and posttranscriptional gene regulation and chromatin assembly. They are believed to be involved in carcinogenic process by promoting tumor cell proliferation, inducing replicative immortality, encouraging evasion of growth suppressors, stimulating angiogenesis and promoting invasion and metastasis [73]. Aside their role in cancer initiation and progression, non-coding RNA can also be exploited as possible biomarkers of $\mathrm{PCa}$ diagnosis, and drug development [74]. There is evidence that ncRNAs are aberrantly expressed in prostate cancer and carcinogenesis and tumor progression may result from series of multicellular activities due to dysregulation of ncRNA controlled pathways [74].

In PCa some lncRNAs are dysregulated and are emerging as major biomarkers of cancer development and therapeutic targets. For example, PCA3, PCATs, SChLAP1, SPRY4-IT1 and TRPM2-AS are lncRNAs upregulated in $\mathrm{PCa}$ [75]. Other studies have demonstrated the role of lncRNAs in regulatory and cellular processes including chromatin modification, alternative splicing, post-transcriptional processing and cell signaling transduction [76]. Dysregulation of their function may have deleterious effects by inducing chromosomal translocation, deletion, and nucleotide expansions. Recent studies demonstrate that multiple prostate cancer risk loci are associated with lncRNAs and that ectopic expression of these transcripts triggers a cascade of cellular events driving tumor initiation and progression [24]. The discovery of the lncRNA prostate cancer antigen 3 (PCA3, or DD3), which is specifically overexpressed in malignant prostate tissue supports the claim that lncRNAs may have cancer-specific expression. These additional lnRNAs AK024556, XLOC_007697, LOC10 0287482, XLOC_005327, XLOC_008559, and XLOC_ 009911 which are differentially expressed in prostatic adenocarcinoma tissue samples could be possible biomarker targets of $\mathrm{PCa}$ [77].

\section{Prostate cancer and microRNA}

MicroRNAs (miRNA) are small, non-coding, singlestranded, short nucleotide sequences (between 19 and 25 nucleotides long) that be derived from lncRNAs and snoRNAs [63]. miRNAs function as regulators of gene expression and influence various physiological and pathophysiological processes [78] by binding to targeted messenger RNA (mRNA) sequences posttranscriptionally through complementary binding and modulate gene expression. They can control gene expression by silencing or degrading targeted mRNA [79]. Deregulation of miRNA in PCa may contribute to cancer initiation and metastatic progression [69]. miRNA can be good biomarker in diagnosing and predicting prognostic outcomes of $\mathrm{PCa}$ as miR-148a is differentially expressed in PCa [69]. Identification of dysregulated microRNAs (miRNAs) in prostate cancer is critical not only for diagnosis, but also differentiation between the aggressive and indolent forms of the disease. Some miRNAs modulate the activities of mesenchymal stem cells (MSCs) especially adipose-derived stromal cell (ASC) that has therapeutic effects on PCa. A novel miR-145 is involved in $\mathrm{PCa}$ cell apoptosis cell induction by mediating the inhibitory effect of ASC on PCa [80]. Understanding the expression patterns of circulating miRNAs and correlating them with disease status could offer an alternative minimally invasive approach to monitor the prognosis of PCa progression [81].

Deregulation of miRNA expression could also have positive outcomes; for example inhibition of miR-9 can reduce tumor growth and metastases by slowing down the migratory and invasive potential of the M12 cell line. miR-9 modulates the expression of e-cadherin and suppressor of cytokine signaling 5 (SOCS5) which cancer linked proteins [82]. Another miRNA, miR-199a-3p targets stemness-related and mitogenic signaling pathways which suppresses the expansion and tumorigenic capabilities of prostate cancer stem cells and aberrant loss of a miRNA-mediated mechanism can lead to the expansion and tumorigenic activity of prostate cancer stem cells (CSCs) [83]. The use of miRNA to silence genes involved in PCa tumorigenesis such as STAMP2 required for PCa progression could be a viable therapeutic mechanism for PCa [40].

Circulating miRNAs could be non-invasive markers of disease and can be used as biomarkers in PCa diagnosis. For example, determining the levels of 15 miRNAs and miR-141 could be used to differentiate metastatic PCa patients from healthy subjects [84] or between $\mathrm{BPH}$ and PCa [85]. But some of the miRNAs are not specific for a particular cancer type and thus, serum miRNAs may distinguish between different cancer types [86]. But miR-21 appears to be elevated in CRPC patients who are resistant to docetaxel than in BPH. While miR-150 enhances targeted endothelial cell migration [87]. miR-26a, miR-195, and let-7i levels were elevated in PCa compared to BPH samples [85]. Other studies have reported additional miRNAs that can be used in $\mathrm{PCa}$ diagnosis. Moltzahn identified 7 miRNAs differentially expressed between PCa patients and healthy subjects 
[88]. For instance, miR-141, and miR-375 expression are elevated in $\mathrm{PCa}$ and their presence in the blood stream may serve as evidence of advanced cancer disease [89]. Further, miR-141 levels have been associated with clinical progression and it is positively correlated with PSA [90]. Both miR-21, miR-221 [91] and miR-141 levels were elevated in $\mathrm{PCa}$ patients compared to healthy controls but the levels were higher in metastatic $\mathrm{PCa}$ than in localized tumors [92]. PCa progression could be monitored by measuring the elevation levels of hsa-miR-141, hsa-miR298 and hsa-miR-375 [93]. Monitoring urinary levels of miR-107 and miR-574-3p could also be relevant in PCa diagnosis [94]. The diagnostic reliability of miRNA in PCa could be further improved by identifying a panel of miRNAs instead of single miRNA. Chen and coworkers identified a panel of 5miRNAin this regard; let-7c, let-7e, miR-30c, miR-622, and miR-1285. According to them this panel could differentiate between PCa patients and healthy people and between PCa and $\mathrm{BPH}$ [95]. miR-20a, miR-21, miR-145, and miR221 can be associated with tumor risk scores [96] while SNORD43 may be a suitable reference gene for the analysis of circulating miRNA in patients with urological malignancies [97].

\section{Prostate cancer and inflammatory oxidative stress}

Prostatic inflammation is suggested to be involved in the pathogenesis and progression PCa [98]. Inflammation is thought to incite carcinogenesis by causing cell and genome damage, promoting cellular turnover [99]. Prostatic inflammation could also be caused by bacterial infections, urine reflux, dietary factors, hormones, and autoimmune response [3]. Irregularities in the functioning of genes involved in oxidative stress have been linked to inflammatory response in PCa. For instance the loss or aberration in the expression of glutathione S-transferase P1 (GSTP1) may contribute to the transition of proliferative inflammatory atrophy (PIA) into high-grade intraepithelial neoplasia (HGIPN) and $\mathrm{PCa}$ in patients with genetic predisposition [3].

Inflammation is known to trigger cytokines production which contributes to tumorigenesis in different tissues. For example, prostaglandin endoperoxide synthase 2, also referred to as cyclooxygenase 2 (COX-2), is an enzyme involved in the conversion of arachidonic acid to prostaglandins and other eicosanoids. The overexpression of COX-2 has been reported to cause phenotypic changes in intestinal epithelial cells that could enhance their tumorigenic potential [100]. COX-2 as a proinflammatory cytokine may also create an environment that favors local growth factor production and angiogenesis in the prostatic tissue [78]. Oxidative stress ensues when the proinflammatory microenvironment creates a local hypoxia induced by increased oxygen demands by proliferating cells leading to tissue injury in infiltrating area [3] (Fig. 4). The literature contains numerous studies associating $\mathrm{PCa}$ and inflammation but none has categorically established a causal relation. Intake of anti-inflammatory drugs and antioxidants leads to a decrease in PCa risk [18]. Further understanding of the role of inflammation in oxidative stress induction and $\mathrm{PCa}$ promotion and progression is necessary as it may revolutionize the way $\mathrm{PCa}$ is treated [16].

\section{Oxidative stress and DNA damage in prostatic hyperplasia}

A genetic predisposition or acquired genetic and epigenetic changes with effect other factors, such as advanced age, race and environmental factors contribute to $\mathrm{PCa}$ development [53]. OS triggers metabolic reprogramming responsible for malignant transformation and tumor development, including invasion and metastasis [101]. The activities of antioxidant enzymes and the levels of antioxidant, reduced glutathione have been found to be significantly decreased in prostatic hyperplasia. Significantly increased levels of oxidative stress and DNA damage suggest that oxidative damage plays an important role in prostate tumorigenesis and timely management of oxidative stress can be of importance in preventing the occurrence of prostatic hyperplasia $[11,16]$. Other studies have revealed that oxidative stress mediated pathways are involved in several male urologic disorders including the different forms of prostatitis (NIH categories IIIa, IIIb, and IV). The new insight into the role of oxidative stress in the pathogenesis of $\mathrm{PCa}$ has led to the exploitation of this mechanism as a potential strategic target for PCa treatment $[30,62]$.

\section{Molecular biology of oxidative stress and prostate cancer} More knowledge about the etiology and progression of $\mathrm{PCa}$ has been provided by the advancement in molecular biology and development of new techniques such as microarray [102] and RNAseq gene expression, genome-wide linkage analysis, and loss of heterozygosity (LOH) [103]. Recently developed methods for profiling genome-wide occupancy of lncRNAs have allowed highthroughput identification of RNA-DNA and RNA-protein interactions. Two methods called Chromatin Isolation by RNA Purification (ChIRP) [104], Native RNA immunoprecipitations sequence(RIP-seq) [105] and CHART, that use complementary oligonucleotides to pull down lncRNAs associated with chromatin, have been developed to determine the chromatin binding sites for lncRNAs. 68 Alternatively, RNA immunoprecipitation sequencing (RIP-Seq) and photoactivatable ribonucleoside-enhanced crosslinking and immunoprecipitation (PAR-CLIP) represent complementary approaches to the study of RNAprotein interactions.69,70 These new techniques represent 
promising tools to explore the mechanisms that govern lncRNA-chromatin interactions, as shown by the informative analyses performed to date on select lncRNAs. Other techniques that have been applied in PCa studies include methods which identify microsatellites, single nucleotide polymorphism (SNP) and haplotype mapping to monitor the distribution of clusters of SNPs that segregate together in linkage disequilibrium [106]. These techniques have revealed the potential role of DNA repair genes, tumor suppressor genes, oncogenes, and protein expression in the prognosis, diagnosis, and possible therapeutic strategies for PCa. Also, linkage analyses in genome wide studies have given clues as to why the disease runs in a family and why a particular race may be at higher risk of developing and dying from the disease [103, 107-111].

Only about $9 \%$ of PCa cases are linked with heredity and studies are carried using multipoint linkage analyses with microsatellite markers. These studies have identified PCa susceptibility loci on chromosome 1, including hereditary PCa families (HPC), HPC1 (1q24-q25), PCAP (1q42-q43), HPCX (Xq27-q28), CAPB (1p36), HPC20 (20q13), HPC2/ELAC2 (17p11) and 16q23 [107, 108, 111]. And based on reports $5 \mathrm{q} 31-\mathrm{q} 33,7 \mathrm{q} 32$ and $19 \mathrm{q} 12$ were described as prostate cancer aggressiveness loci [103]. Although inconsistent results were obtained from repeated linkage studies of these regions, HPC1 is thought be common among people with early onset disease. Nevertheless, hereditary of PCa is heterogeneous and there are multiple loci on chromosome 1 for this disease [103, 107, 108].

Genetics is a major determinant of susceptibility to PCa on a wide population [112]. Aberrations in gene expression and gene mutations have been seen in prostate cancer including PTEN, KAI1, SRD5A2, and IL6 and they are associated with $\mathrm{PCa}$ progression [113]. Genomewide studies have revealed multiple loci that can bind to $\mathrm{PCa}$ candidate susceptibility genes such as MSMB, LMTK2 and KLK3, CPNE3, IL16 and CDH13. For example MSMB which encodes beta-microseminoprotein, a primary constituent of semen and a potential prostate cancer biomarker, and CTBP2, a gene with antiapoptotic activity are located on chromosome $10[109,110]$. Genes associated with the redox homeostasis of the cell are being reported to undergo transformation that influences susceptibility to PCa. Of particular interest is the six transmembrane protein of prostate 2 (STAMP2) which is an androgen-regulated gene whose mRNA expression is increased in PCa. The STAMP2 protein expression is increased in human PCa. It is suggested that STAMP2 also significantly increases reactive oxygen species (ROS) in PCa cells because its iron reductase activity has the ability to deplete NADPH levels [40].

A search for prostate cancer/molecular biology on Cancer Index Web Resource and NCBI [50, 113] was used to construct Table 2 which shows a list of genes that are associated with PCa based on scientific publications. The table is not exhaustive and most of genes are known to regulate critical mechanisms in other types of cancer. The list includes the gene symbols, gene names, and their location on the chromosome and the number of scientific publications on each of the genes (Table 2). Genes that regulate critical mechanisms in other cancers and which are expressed in prostate cancer include Kallikrein-related peptidase 3 (KLK3), also referred to as prostate surface antigen (PSA) [50, 113]. PSA is elevated in PCa and serum measurement of PSA is a common diagnostic test for diagnosis and monitoring of $\mathrm{PCa}$ in hospital settings [114]. CD82 molecule, a metastasis suppressor gene product known to be downregulated in tumor progression of human cancers and can be activated by p53. It is co-expressed with p53 and aberration in CD82 expression is linked with poor survival for $\mathrm{PCa}$ patients [115]. Another gene in Table 2 is microseminoprotein, beta (MSMB) which encodes a protein that belongs to the immunoglobulin binding factor family. The protein is synthesized by the epithelial cells of the prostate gland and secreted into the seminal plasma. This protein has inhibin-like activity and its expression decreases in PCa [116, 117]. A tumor suppressor gene, Ras association (RalGDS/AF-6) domain family member 1 (RASSF1) has been seen in other cancers and is believed to play a role in PCa pathogenesis [118]. Clusterin on the other hand encodes a protein that regulates several basic biological events including cell death, tumor progression, and neurodegenerative disorders [119]. NK3 homeobox 1 (NKX3-1) encodes a homeobox-containing transcription factor which serves as a negative regulator of epithelial cell growth in prostate tissue. Aberrant expression of this gene is associated with prostate tumor progression [111].

Prostate stem cell antigen (PSCA) encodes a glycosylphosphatidylinositol-anchored cell membrane glycoprotein and it is secreted in the prostate as well as in other organs such as the colon and pancreas. PSCA is upregulated in a large proportion in $\mathrm{PCa}$ and is also detected in cancers of the bladder and pancreas [120]. Pten is also associated with different types of malignancies and it is known to be involved in $\mathrm{PCa}$ development where it coordinates the differentiation and proliferation of cell types [121]. ELAC ribonuclease 2 (ELAC2) functions as a transcription factor. It interacts with activated Smad family member $2(\operatorname{Smad} 2)$ and its nuclear partner forkhead box H1 (FAST-1). Mutations in this gene may lead to an increased risk of PCa [122, 123]. PCa-associated 3 (PCA3) produces a spliced, long non-coding RNA that is highly overexpressed in most types of prostate cancer cells and is used as a specific biomarker for this type of cancer [83]. Glutathione S-transferase mu 1 (GSTM1) is involved in detoxifying electrophilic compounds and neutralizing 
Table 2 List of Genes Associated with Prostate Cancer and Oxidative Stress. [50, 113]

\begin{tabular}{|c|c|c|c|}
\hline Gene & Gene name & Location & Papers \\
\hline KLK3 & Kallikrein-related peptidase 3 & $19 q 13.41$ & 3000 \\
\hline$A R$ & Androgen receptor & $\mathrm{Xq12}$ & 1221 \\
\hline MKI67 & Marker of proliferation Ki-67 & $10 \mathrm{q} 26.2$ & 424 \\
\hline PTEN & Phosphatase and tensin homolog & $10 q 23.3$ & 376 \\
\hline TP53 & Tumor protein p53 & $17 p 13.1$ & 343 \\
\hline TMPRSS2 & Transmembrane protease, serine 2 & $21 q 22.3$ & 336 \\
\hline CTNNB1 & Catenin (cadherin-associated protein), beta 1 & $3 p 21$ & 312 \\
\hline BRCA1 & Breast cancer 1 , early onset & $17 q 21$ & 178 \\
\hline BRCA2 & Breast cancer 2, early onset & $13 q 12.3$ & 156 \\
\hline PROC & Protein C (inactivator of coagulation factors Va and VIlla) & $2 q 13-q 14$ & 135 \\
\hline CDKN1A & Cyclin-dependent kinase inhibitor 1A (p21, Cip1) & $6 \mathrm{p} 21.2$ & 125 \\
\hline NKX3-1 & NK3 homeobox 1 & $8 p 21.2$ & 120 \\
\hline SRD5A2 & Steroid-5-alpha-reductase, & $2 p 23$ & 120 \\
\hline SRC & SRC proto-oncogene, non-receptor tyrosine kinase & $20 q 12-q 13$ & 97 \\
\hline KITLG & KIT ligand & $12 q 22$ & 93 \\
\hline CDKN1B & Cyclin-dependent kinase inhibitor 1B (p27, Kip1) & 12p13.1-p12 & 92 \\
\hline CD44 & CD44 molecule (Indian blood group) & $11 p 13$ & 87 \\
\hline TGFB1 & Transforming growth factor, beta 1 & $19 q 13.1$ & 83 \\
\hline HIF1A & Hypoxia inducible factor 1, alpha subunit (basic helix-loop-helix transcription factor) & $14 q 23.2$ & 82 \\
\hline CYP17A1 & Cytochrome P450, family 17 , subfamily A, polypeptide 1 & $10 \mathrm{q} 24.3$ & 82 \\
\hline PTGS2 & Prostaglandin-endoperoxide synthase 2 (prostaglandin $\mathrm{G} / \mathrm{H}$ synthase and cyclooxygenase) & $1 q 25.2-q 25.3$ & 81 \\
\hline PPARG & Peroxisome proliferator-activated receptor gamma & $3 p 25$ & 81 \\
\hline PCA3 & Prostate cancer associated 3 (non-protein coding) & $9 q 21.2$ & 78 \\
\hline IGFBP3 & Insulin-like growth factor binding protein 3 & $7 \mathrm{p} 12.3$ & 76 \\
\hline $\mathrm{EZH} 2$ & Enhancer of zeste 2 polycomb repressive complex 2 subunit & $7 q 35-q 36$ & 75 \\
\hline ETV1 & ETS (E twenty-six) variant 1 & $7 \mathrm{p} 21.3$ & 73 \\
\hline GSTM1 & Glutathione S-transferase mu 1 & $1 \mathrm{p} 13.3$ & 72 \\
\hline$J U N$ & Jun proto-oncogene & 1 p32-p31 & 65 \\
\hline CAMP & Cathelicidin antimicrobial peptide & $3 p 21.3$ & 61 \\
\hline ELAC2 & ElaC ribonuclease Z 2 & 17p11.2 & 56 \\
\hline SERPINB5 & Serpin peptidase inhibitor, clade B (ovalbumin), member 5 & $18 q 21.33$ & 54 \\
\hline CD82 & CD82 molecule & $11 p 11.2$ & 50 \\
\hline AMACR & Alpha-methylacyl-CoA racemase & $5 p 13$ & 50 \\
\hline IGF1R & Insulin-like growth factor 1 receptor & $15 q 26.3$ & 49 \\
\hline IL10 & Interleukin 10 & $1 q 31-q 32$ & 47 \\
\hline $\mathrm{E} 2 \mathrm{~F} 1$ & E2F transcription factor 1 & $20 q 11.2$ & 46 \\
\hline MSMB & Microseminoprotein, beta- (10q11.2) & $10 q 11.2$ & 45 \\
\hline TRPM2 & Transient receptor potential cation channel, subfamily M, member 2 & $21 q 22.3$ & 44 \\
\hline CYP3A4 & Cytochrome P450, family 3, subfamily A, polypeptide 4 & $7 q 21.1$ & 43 \\
\hline CLU & Clusterin & $8 p 21-p 12$ & 43 \\
\hline PSCA & Prostate stem cell antigen & $8 q 24.2$ & 42 \\
\hline FOS & FBJ murine osteosarcoma viral oncogene homolog & $14 q 24.3$ & 42 \\
\hline CASP9 & Cysteine-aspartic acid protease (caspase) 9, apoptosis-related cysteine peptidase & $1 \mathrm{p} 36.21$ & 40 \\
\hline VEGFA & Vascular endothelial growth factor A & $6 p 12$ & 40 \\
\hline
\end{tabular}


Table 2 List of Genes Associated with Prostate Cancer and Oxidative Stress. [50, 113] (Continued)

\begin{tabular}{|c|c|c|c|}
\hline FOXA1 & Forkhead box A1 & $14 q 21.1$ & 40 \\
\hline MET & MET proto-oncogene, receptor tyrosine kinase & $7 q 31$ & 40 \\
\hline CYP3A5 & Cytochrome P450, family 3, subfamily A, polypeptide 5 & $7 q 21.1$ & 39 \\
\hline RASSF1 & Ras association (RalGDS/AF-6) domain family member 1 & $3 p 21.3$ & 39 \\
\hline PDLIM4 & PDZ and LIM domain 4 & $5 q 31.1$ & 38 \\
\hline MSR1 & Macrophage scavenger receptor 1 & $8 p 22$ & 38 \\
\hline
\end{tabular}

the effect of anti-oxidants in the cellular system, glutathione conjugates with the products of oxidative stress $[124,125]$. Prostaglandin-endoperoxide synthase 2 (PTGS), also known as cyclooxygenase, is the key enzyme in prostaglandin biosynthesis, and acts both as a dioxygenase and as a peroxidase. This gene encodes inducible isozyme which induces prostanoid biosynthesis. Prostanoid is thought to be involved in inflammation and mitogenesis [124]. Hypoxia inducible factor 1 , alpha subunit (HIF1A) encodes the alpha subunit of transcription factor hypoxiainducible factor-1 (HIF-1), which is a heterodimer consisting of an alpha and a beta subunit. HIF-1 is involved in the regulation of cellular and systemic homeostatic response to hypoxia. It activates transcription of genes involved in energy metabolism, angiogenesis, apoptosis, and other genes that secret protein which promote metabolic adaptation to hypoxic environment as well as increase oxygen delivery. It may also be involved in the activation of signaling pathways. Redox-sensitive transcription factors like HIF- $1 \alpha$ has been shown to play a major role in progression and metastasis of the cancer cells [126]. Steroid-5-alpha-reductase (SRD5A2) gene encodes a microsomal protein expressed at high levels in androgen-sensitive tissues such as the prostate and male pseudohermaphroditism, specifically pseudovaginal perineoscrotal hypospadias may occur if the gene is suppressed or deficient [127].

Cellular dysfunction resulting from polymorphisms and post translation modifications such as methylation in genes contributes to PCa risk. For instance, changes in the glutathione S-transferase (GST) genes have been implicated as risk factors for prostate cancer [128]. Loss of GSTP1 expression via promoter hypermethylation is the most common epigenetic alteration observed in human PCa. Dysfunction of GSTP1, a member of the GST gene family, can trigger an increased production of reactive oxygen species (ROS) and DNA damage in cells. Thus, monitoring GSTP1 expression in human prostate cells may be an important target for primary prevention of PCa knowing that in its absence cells are more prone to oxidative stress induced DNA damage and cell death [129]. The GST superfamily consists of four gene classes (A, M, T, and P) encoding for enzymes which catalyze the conjugation of electrophilic compounds to glutathione [130]. These enzymes are also believed to play a crucial role in the protection of DNA from oxidative damage [131]. The pi-class glutathione S-transferase (GSTP1) actively protect cells from carcinogens and electrophilic compounds. Previous studies have shown that the CpG-rich promoter region of the pi-class gene GSTP1 is methylated at single restriction sites in the most prostate cancers $[132,133]$. It has been observed that in normal prostate tissue the entire CpG island is unmethylated but outside the island in the body of the gene is highly methylated. The DNA methylation of the CpG island in both PCa cell lines and cancer tissues occurs when GSTP1 expression is repressed [128]. Tumor suppressor genes and other $\mathrm{CpG}$ island-containing genes such as calcitonin, p15, p16, Rb, VHL, e-cadherin, ER, and HIC1 have been found in the hypermethylated region [97].

There are other polymorphs of GST such as the mu (GSTM1) and theta (GSTT1) which regulate the conjugation of carcinogenic compounds to excretable hydrophilic metabolites making the genes more susceptible to various carcinogens. Changes in their structure such as double deletion (GSTM1-/GSTT1-) is associated with higher oxidative stress which might exacerbate the pathogenesis of $\mathrm{BPH}$ and $\mathrm{PCa}$ [36]. In normal prostate, the transduction pathway from NIK to NF-kB seems to be inactive. However, in $\mathrm{BPH}$, it has been reported that TNF- $\alpha$ /AP-1 transduction pathway is activated followed by a stimulation of the apoptotic pathway to inhibit uncontrolled cell proliferation [134]. Another study has also demonstrated a novel link between OS and loss of imprinting, showing that OS as measured by the increase in NF-kB activity, induces loss of imprinting of insulin-like growth factor 2 in both cancerous and noncancerous human prostate cells (Fig. 5). This loss during aging contributes to tumorigenesis and NF-kB modulation is important as it may prevent age-related alteration in the epigenome [24].

PCa tumorigenesis involves a combo of genes such as the antioxidant enzyme heme oxygenase 1 (HMOX1/HO1) which is responsible for the maintenance of the cellular homeostasis (See Fig. 6). HMOX1/HO-1 plays a critical role in oxidative stress mechanism and in the regulation of PCa development and progression. The transcription factor $\mathrm{Nrf} 2$ and BRCA1 protein synergistically activate 


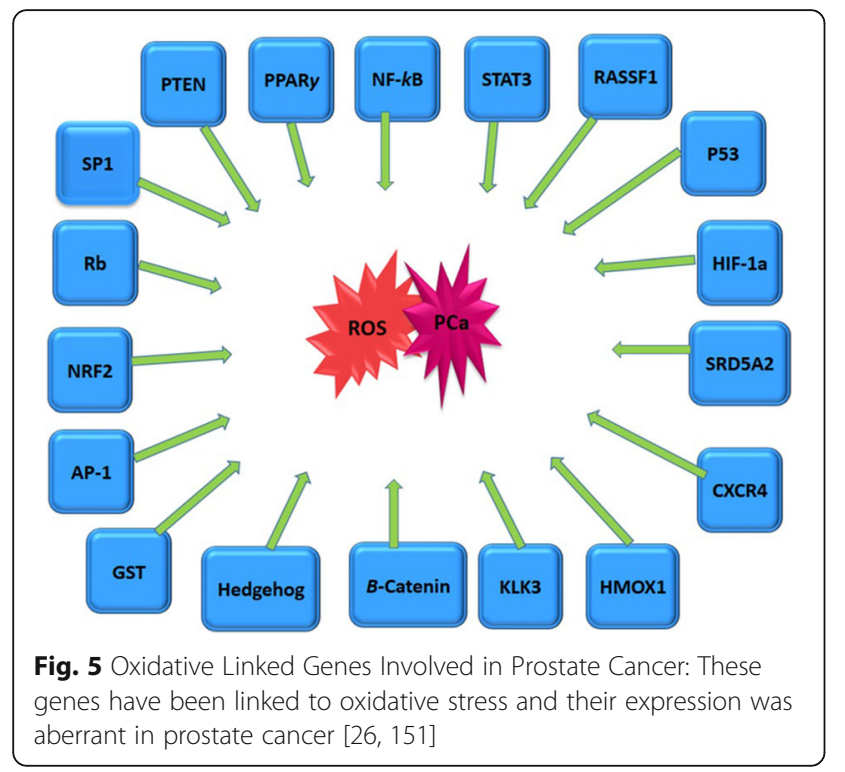

HO-1 promoter activity forming BRCA1-Nrf2/HO-1 which function in the maintenance of the cellular homeostasis in PCa. They exert both oxidative and genotoxic stress on HO-1 transcriptional activity [135]. ROS increase the expression and activity of the chemokine receptor, cysteine (C)-X-C Receptor 4 (CXCR4), which enhances metastatic functions in prostate cancer cells. Also, CXCR4 and its ligand, SDF- $1 \alpha$, promote ROS accumulation contributed by the NADPH oxidase (NOX) family of enzymes. NOX2 expression is associated with PCa. CXCR4/ SDF- $1 \alpha$-mediated ROS production through NOX2 enzymes may be an emerging concept by which chemokine signaling progresses tumorigenesis [136]. Glyoxalase 1 (GLO1) is a glutathione-dependent enzyme that acts as a scavenging enzyme. It participates in ROS mechanism and is involved in the occurrence and progression of human malignancies. Polymorphism in Glyoxalase I A111E may influence its enzymatic activity. GLO1 could be important in PCa progression and may be a good marker for risk assessment and prognosis in PCa patients [137]. Another gene, prostate-associated gene 4 (PAGE4) encodes a

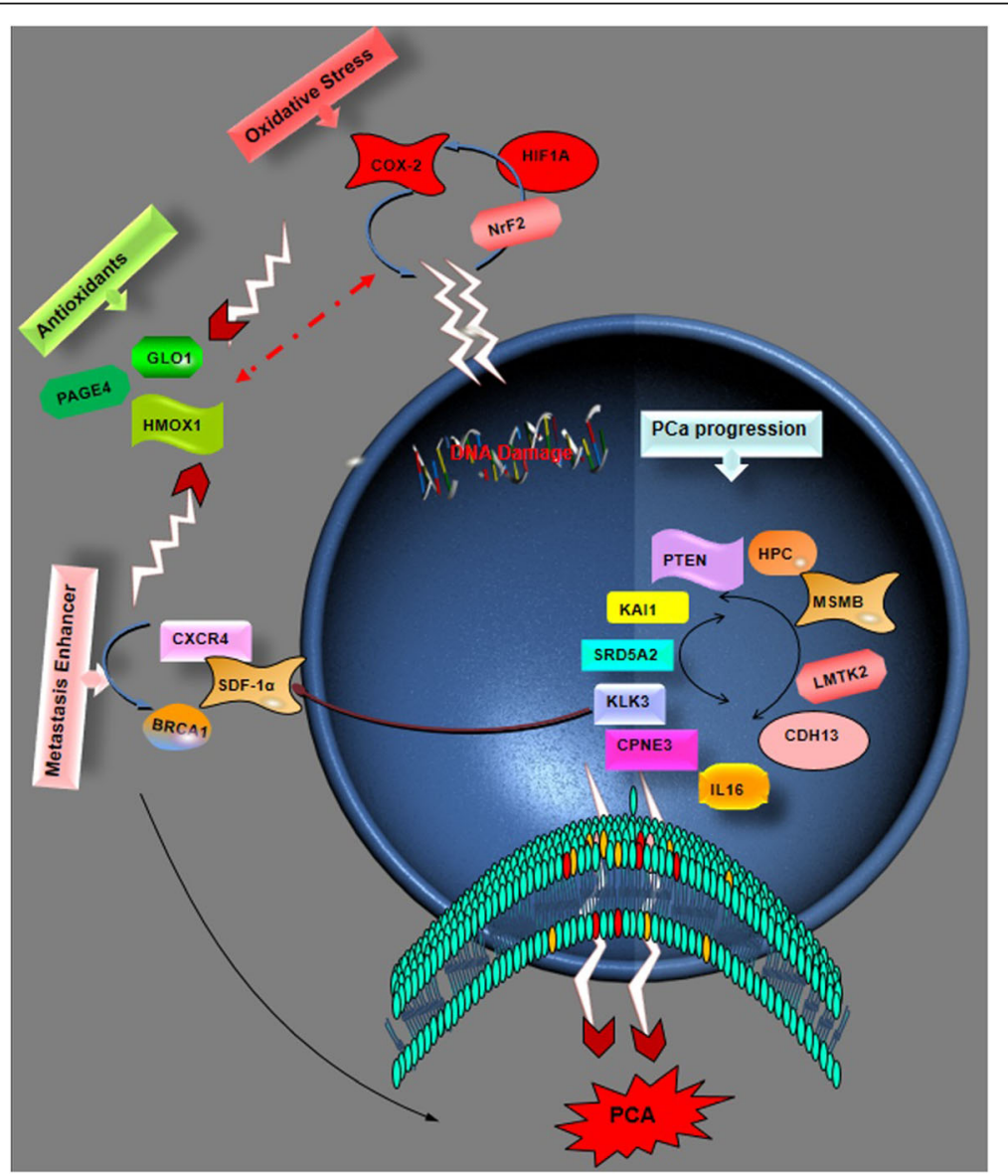

Fig. 6 Gene Involved in the signaling pathways which contribute to the development and progression (including invasion, metastasis, and relapse) of PCa: The genes that maintain hemostasis receive attack from pro-oxidative stress genes and genes that are involved in metastasis. DNA damage leads to suppression of antioxidant pro-gene and this gives way to the over-expression of cancer promoting genes 
protein which protects cells against stress by elevating p21 and suppressing ROS production. PAGE4 is a cancer/ testis antigen (CTA) that is up-regulated in PCa and seen in symptomatic patients. However, PAGE4 appears to protect cells from transforming to $\mathrm{PCa}$ by its stressprotective and anti-apoptotic activities [138]. The role of OS and diet in PCa mechanism was observed with the prostate-specific ablation of PPAR $\gamma$ in mice. This action resulted in tumorigenesis and active autophagy. Placing the mice on high-fat diet (HFD) caused downregulation of PPAR $\gamma$-regulated genes and decreased prostate differentiation. This suggests that systemic metabolic stress occurs in glucose and fatty acid metabolism in benign and $\mathrm{PCa}$ [67].

Pyruvate kinase M2 (PKM2) is essential for aerobic glycolysis, the dominant metabolic pathway utilized by cancer cells. To determine the association of PKM2 with prostate cancer (PC). PKM2 was found to be upregulated and undergoes post translational modification in PCa [139]. Pten as shown in Table 2 is involved in PCa cellular programing and signaling and G6PD metabolism. AR signaling can promote prostate cancer through the upregulation of G6PD and thus providing sugars via the pentose phosphate pathway. This suggests there are other metabolic pathways apart from the glycolysis which prostate cancer growth can be promoted and sustained [140].

Dietary factors are considered responsible for the geographical differences in prostate cancer incidence and mortality. Since about $50 \%$ of all men worldwide, from both East and West, show evidence of microscopic cancer by 50 years of age, growth restraint would appear to be the pragmatic option to the possibility of preventing initiation [141].

Preventive effects of antioxidants against prostate cancer Published research has shown that the antioxidant defense system is decreased in the elderly patients with $\mathrm{PCa}$ and $\mathrm{BPH}$ [66]. The 2-hydroxy-4-methoxy benzoic acid (HMBA), is an antioxidant that has been shown to have protective potential against testosterone induced $\mathrm{BPH}$ in rats [29]. Chemopreventive effects of the essential trace element selenium against prostate cancer have been shown in preclinical models and human observational studies, but results from clinical trials have been disappointing. It appears that there is a threshold selenium (Se) status below which improvement will decrease PCa risk, but above which supplemental Se may be deleterious. Different forms of selenium have different effects, and genetic and other factors modify selenium's chemopreventive potential [23]. However, there has been reduced interest in pursuing chemoprevention strategies targeting oxidative stress because of the failure of the Selenium and Vitamin E Cancer Prevention Trial
(SELECT) [72]. Another promising therapeutic candidate is comprised of plant-derived dietary polyphenolic compounds, such as flavonoids that have cancer cellspecific pro-apoptotic activity and chemopreventive potential. Flavonoid glycosides are also found to be DNA hypomethylating agents with an ability to modulate cancer cell epigenome leading to changes in the gene expression patterns. For example, diosmin which is a dietary flavonoid glycoside was found to be active against DU145 cells by promoting genotoxic events that led to apoptotic cell death [142].

\section{Oxidative stress, antioxidants and prostate cancer treatment}

The classical treatment involves bilateral orchiectomy, or administration of diethylstilbestrol (DES). Other treatment strategies are based on endocrine treatment. The principle for endocrine treatment of prostate cancer is to deprive the cancer cells of androgens. Androgen deprivation is an effective treatment for patients with advanced prostate cancer but it is not curative and creates unwanted side effects [143]. For metastatic PCA, castration is still the best choice of treatment as orchiectomy, oestrogen agonists and GnRH agonists produce equivalent clinical responses [144]. It is interesting to note that maximum androgen blockade (MAB) is not strikingly more effective than single agent $\mathrm{GnRH}$ agonist or orchiectomy. However, for locally advanced PCA, nonsteroidal antiandrogen monotherapy is as effective as castration [144].

Although oxidative stress has been associated with several destructive mechanisms in biological systems, induction of oxidative stress can also provide a means for a potent and safe cancer treatment [145]. Oxidative stress has been shown to promote castration resistance via androgen receptor (AR)-dependent pathway such as AR overexpression, AR cofactor, and AR post-translational modification as well as AR-independent pathway, leading to the emergence of castration-resistant $\mathrm{PCa}$ (CRPC). Thus antioxidants therapy using natural and chemical ROS scavengers and inhibitors of ROS production seems to be a promising therapy for CRPC as well as preventing castration resistance [146]. Androgen deprivation therapy (ADT) has been reported to lower basal ROS level in prostate cancer $(\mathrm{PCa})$ and to sensitize $\mathrm{PCa}$ to radiation. An in vivo experiment with transgenic adenocarcinoma of the mouse prostate (TRAMP) androgen deprivation resulted in an increase in basal ROS level in PCa cells with AR expression. also, the genetic Nrf2 upregulation lowered basal ROS similar to ADT [147].

The major androgen within the prostate is dihydrotestosterone (DHT). DHT and 5 $\alpha$-reductase are highly associated with prostate cancer. It has been hypothesized that inhibition of $5 \alpha$-reductase activity might reduce the risk of prostate cancer development, slow tumor 
progression and even treat the existing disease. The therapeutic mechanism of some of the most recommended drugs for prostatic hyperplasia treatment, 5ARIs, is based on their reductive effect on testosterone, progesterone, androstenedione, cortisol, aldosterone, and deoxycorticosterone [148]. For example, dutasteride (Avodart) suppresses all three $5 \alpha$-reductase isoenzymes and reduces dihydrotestosterone in men with benign prostatic hyperplasia [149]. Exposure of human PCa cells to KML001 (NaAsO2, sodium metaarsenite, Kominox), an orally bioavailable arsenic compound, induces both apoptotic and autophagic cell death via oxidative stress pathway. Also, KML001 has an antiproliferative effect on DU145 cells in xenograft mice [37]. It has been reported that the therapeutic silencing of STAMP2 by administration of nanoliposomal siRNA profoundly inhibits tumor growth in two established preclinical $\mathrm{PCa}$ models in mice. These findings suggest that STAMP2 is required for $\mathrm{PCa}$ progression and thus may serve as a novel therapeutic target [40]. There is evidence that $\alpha$ ATA $(8,24) \quad(3 \alpha$-acetyloxy-tir-8,24-dien-21-oic acid) inhibits Akt/mammalian target of rapamycin (mTOR) signaling. Compared with related tirucallic acids, $\alpha$ ATA $(8,24)$ is the most potent inhibitor of the proliferation of androgen-insensitive PCa cells in vitro and in vivo. In PCa xenografted onto chick chorioallantoic membranes aATA $(8,24)$ induced loss of cell membrane asymmetry, caspase- 3 activation, and DNA fragmentation in vitro and in vivo. The ability of aATA $(8,24)$ to inhibit Akt/mTOR signaling and to simultaneously induce oxidative stress could be exploited for the development of novel antitumor therapeutics with a lower profile of toxic side effects [70].

\section{Conclusions}

This review has demonstrated that there are several studies which support the fact that oxidative stress plays a critical role in PCa. This oxidative damage is mediated by an overproduction of oxidant molecules and concomitant deficiency in the antioxidant system response which causes an imbalance in the cell redox homeostasis. $\mathrm{PCa}$ is associated with both age, and oxidative stress which also contributes to the aging process. Oxidative stress affects all aspects of cellular functions and processes including DNA replication and cell division, and inflammatory responses. Both endogenous and exogenous antioxidants contribute to the reduction of PCa by neutralizing the damaging effect of oxidative stress. However, the oxidative mechanism can also be exploited for treatment of prostate related diseases including PCa.

\section{Acknowledgement}

We gratefully acknowledge all members of RCMI-Center for Environmental Health-External Advisory Committee for their support and encouragements.

\section{Funding}

This research was supported by a grant from the National Institutes of Health/National Institute on Minority Health and Health Disparities (G12MD007581) through the RCMI Center for Environmental Health at Jackson State University.

\section{Availability of data and supporting materials}

Not applicable. Data sharing not applicable to this article as no datasets were generated or analyzed during the current study.

\section{Authors' contributions}

UKU and PBT conceived and designed the outline. UKU did the literature search and drafted the manuscript. PBT reviewed and finalized the manuscript for submission.

\section{Authors' information}

Udensi K. Udensi, PhD, MPH, MB(ASCP) ${ }^{\mathrm{cm}}$, Research Associate The RCMI

Center for Environmental Health, Jackson State University, Jackson MS 39217.

Paul B. Tchounwou, Sc.D., F.A.B.I., I.O.M., Associate Dean \& Presidential

Distinguished Professor, Director, NIH, RCMI-Center for Environmental Health,

Jackson State University, 1400 Lynch Street, Box 18750, Jackson, MS 39217.

Competing interests

The authors declare that they have no competing interests.

Consent for publication

Not applicable.

Ethical approval and consent to participate

Not applicable.

Received: 10 May 2016 Accepted: 6 September 2016

Published online: 08 September 2016

\section{References}

1. Prostate Cancer FAQS. Prostate Cancer Foundation. http://www.pcf.org/site/ c.leJRIROrEpH/b.5800851/k.645A/Prostate_Cancer_FAQs.htm. Accessed 15 Apr 2016.

2. Cancer Among Men, Center For Disease Control and Prevetion. http://www. cdc.gov/cancer/dcpc/data/men.htm. Accessed 15 Apr 2016.

3. Awodele O, Adeyomoye AA, Awodele DF, Fayankinnu VB, Dolapo DC. Cancer distribution pattern in south-western Nigeria. Tanzan J Health Res. 2011;13(2):125-31.

4. Theodorescu D. Prostate Cancer: Management of Localized Disease. 2004. www.emedicine.com.

5. Small E. Cecil Textbook of Medicine, Prostate Cancer. WB Saunders, an Elsevier imprint. 2004

6. Cameron KS, Howard CB, Izevbigie EB, Hill BJ, Tchounwou PB. Sensitivity and mechanisms of taxol-resistant prostate adenocarcinoma cells to Vernonia amygdalina extract. Exp Toxicol Pathol. 2013;65(6):759-65.

7. Udensi UK, Tchounwou PB. Dual effect of oxidative stress on leukemia cancer induction and treatment. J Exp Clin Cancer Res. 2014;33:106.

8. Seddon M, Looi YH, Shah AM. Oxidative stress and redox signalling in cardiac hypertrophy and heart failure. Heart. 2007;93(8):903-7.

9. Minciullo PL, Inferrera A, Navarra M, Calapai G, Magno C, Gangemi S. Oxidative stress in benign prostatic hyperplasia: a systematic review. Urol Int. 2015;94(3):249-54.

10. Aryal M, Pandeya A, Bas BK, Lamsal M, Majhi S, Pandit R, Agrawal CS, Gautam N, Baral N. Oxidative stress in patients with benign prostate hyperplasia. JNMAJ Nepal Med Assoc. 2007;46(167):103-6.

11. Aydin A, Arsova-Sarafinovska Z, Sayal A, Eken A, Erdem O, Erten K, Ozgok Y, Dimovski A. Oxidative stress and antioxidant status in non-metastatic prostate cancer and benign prostatic hyperplasia. Clin Biochem. 2006;39(2): 176-9.

12. Battisti V, Maders LD, Bagatini MD, Reetz LG, Chiesa J, Battisti IE, Goncalves JF, Duarte MM, Schetinger MR, Morsch VM. Oxidative stress and antioxidant status in prostate cancer patients: relation to Gleason score, treatment and bone metastasis. Biomed Pharmacother. 2011;65(7):516-24.

13. Cimino S, Favilla V, Russo Gl, Galvano F, Li VG, Barbagallo I, Giofre SV, D'Orazio N, Di RA, Madonia M, et al. Oxidative stress and body composition 
in prostate cancer and benign prostatic hyperplasia patients. Anticancer Res. 2014;34(9):5051-6.

14. Duru R, Njoku O, Maduka I. Oxidative stress indicators in patients with prostate disorders in Enugu, South-East Nigeria. Biomed Res Int. 2014;2014: 313015

15. Ripple MO, Henry WF, Rago RP, Wilding G. Prooxidant-antioxidant shift induced by androgen treatment of human prostate carcinoma cells. J Natl Cancer Inst. 1997;89(1):40-8.

16. Bostanci Y, Kazzazi A, Momtahen S, Laze J, Djavan B. Correlation between benign prostatic hyperplasia and inflammation. Curr Opin Urol. 2013;23(1):5-10.

17. Shankar E, Bhaskaran N, Maclennan GT, Liu G, Daneshgari F, Gupta S. Inflammatory Signaling Involved in High-Fat Diet Induced Prostate Diseases. J Urol Res. 2015;2(1)2018.

18. Sugar LM. Inflammation and prostate cancer. Can J Urol. 2006;13 Suppl 1:46-7.

19. He JH, Zhang JZ, Han ZP, Wang L, LV YB, Li YG. Reciprocal regulation of PCGEM1 and miR-145 promote proliferation of LNCaP prostate cancer cells. J Exp Clin Cancer Res. 2014;33:72.

20. Jones RA, Underwood SM, Rivers BM. Reducing prostate cancer morbidity and mortality in African American men: issues and challenges. Clin J Onco Nurs. 2007;11(6):865-72.

21. Almushatat AS, Talwar D, McArdle PA, Williamson C, Sattar N, O'Reilly DS, Underwood MA, McMillan DC. Vitamin antioxidants, lipid peroxidation and the systemic inflammatory response in patients with prostate cancer. Int J Cancer. 2006;118(4):1051-3.

22. Chang SN, Han J, Abdelkader TS, Kim TH, Lee JM, Song J, Kim KS, Park JH, Park JH. High animal fat intake enhances prostate cancer progression and reduces glutathione peroxidase 3 expression in early stages of TRAMP mice. Prostate. 2014;74(13):1266-77.

23. Christensen MJ. Selenium and prostate cancer prevention: what next-if anything? Cancer Prev Res (Phila). 2014;7(8):781-5.

24. Li C, Yang L, Lin C. Long noncoding RNAs in prostate cancer: mechanisms and applications. Mol Cell Oncol. 2014;1(3):e963469.

25. El GM, Buchele B, Syrovets T, Agnolet S, Schneider B, Schmidt CQ, Simmet T. An alpha-acetoxy-tirucallic acid isomer inhibits Akt/mTOR signaling and induces oxidative stress in prostate cancer cells. J Pharmacol Exp Ther. 2015; 352(1):33-42.

26. Gupta-Elera G, Garrett AR, Robison RA, O'Neill KL. The role of oxidative stress in prostate cancer. Eur J Cancer Prev. 2012;21(2):155-62.

27. Khandrika L, Kumar B, Koul S, Maroni P, Koul HK. Oxidative stress in prostate cancer. Cancer Lett. 2009;282(2):125-36.

28. Merendino RA, Salvo F, Saija A, Di PG, Tomaino A, Minciullo PL, Fraccica G, Gangemi S. Malondialdehyde in benign prostate hypertrophy: a useful marker? Mediators Inflamm. 2003;12(2):127-8.

29. Ahmad M, Suhail N, Mansoor T, Banu N, Ahmad S. Evaluation of oxidative stress and DNA damage in benign prostatic hyperplasia patients and comparison with controls. Indian J Clin Biochem. 2012;27(4):385-8.

30. Srivastava DS, Mittal RD. Free radical injury and antioxidant status in patients with benign prostate hyperplasia and prostate cancer. Indian J Clin Biochem. 2005:20(2):162-5.

31. Arsova-Sarafinovska Z, Eken A, Matevska N, Erdem O, Sayal A, Savaser A, Banev S, Petrovski D, Dzikova S, Georgiev V, et al. Increased oxidative/ nitrosative stress and decreased antioxidant enzyme activities in prostate cancer. Clin Biochem. 2009:42(12):1228-35.

32. Pace G, Di MC, De AD, Corbacelli C, Di RL, Vicentini C, Miano L, Tozzi Ciancarelli MG. Oxidative stress in benign prostatic hyperplasia and prostate cancer. Urol Int. 2010;85(3):328-33.

33. Teillac $P$, Peyret $C$, Leroy $M$, Najean $Y$, Le DA. [Prostate-specific antigen in prostatic pathology]. Ann Urol (Paris). 1988;22(3):193-6.

34. Iguchi T, Wang CY, Delongchamps NB, Kato M, Tamada S, Yamasaki T, de la Roza G, Nakatani T, Haas GP. Association of MnSOD AA Genotype with the Progression of Prostate Cancer. PLoS One. 2015;10(7):e0131325.

35. Kotrikadze N, Alibegashvili M, Zibzibadze M, Abashidze N, Chigogidze T, Managadze L, Artsivadze K. Activity and content of antioxidant enzymes in prostate tumors. Exp Oncol. 2008;30(3):244-7.

36. Kumar V, Yadav CS, Datta SK, Singh S, Ahmed RS, Goel S, Gupta S, Mustafa M, Grover RK, Banerjee BD. Association of GSTM1 and GSTT1 polymorphism with lipid peroxidation in benign prostate hyperplasia and prostate cancer: a pilot study. Dis Markers. 2011;30(4):163-9.

37. Azoulay L, Eberg M, Benayoun S, Pollak M. 5alpha-reductase inhibitors and the risk of cancer-related mortality in men with prostate cancer. JAMA Oncol. 2015;1(3):314-20.
38. Baltaci S, Orhan D, Gogus C, Turkolmez K, Tulunay O, Gogus O. Inducible nitric oxide synthase expression in benign prostatic hyperplasia, low- and high-grade prostatic intraepithelial neoplasia and prostatic carcinoma. BJU Int. 2001:88(1):100-3.

39. Bidoli E, Talamini R, Zucchetto A, Bosetti C, Negri E, Lenardon O, Maso LD, Polesel J, Montella M, Franceschi S, et al. Dietary vitamins E and C and prostate cancer risk. Acta Oncol. 2009;48(6):890-4.

40. Bai XY, Qu X, Jiang X, Xu Z, Yang Y, Su Q, Wang M, Wu H. Association between dietary vitamin $\mathrm{c}$ intake and risk of prostate cancer: a metaanalysis involving 103,658 subjects. J Cancer. 2015;6(9):913-21.

41. Maramag C, Menon M, Balaji KC, Reddy PG, Laxmanan S. Effect of vitamin C on prostate cancer cells in vitro: effect on cell number, viability, and DNA synthesis. Prostate. 1997:32(3):188-95.

42. Thieu W, Tilki D, de Vere White RW, Evans CP. The role of microRNA in castration-resistant prostate cancer. Urol Oncol. 2014;32(5):517-23.

43. Evans $P$, Halliwell B. Micronutrients: oxidant/antioxidant status. Br J Nutr 2001:85 Suppl 2:S67-74.

44. Manzanares W, Dhaliwal R, Jiang X, Murch L, Heyland DK. Antioxidant micronutrients in the critically ill: a systematic review and meta-analysis. Crit Care. 2012;16(2):R66

45. Kristal AR, Till C, Song X, Tangen CM, Goodman PJ, Neuhauser ML, Schenk JM, Thompson IM, Meyskens Jr FL, Goodman GE, et al. Plasma vitamin D and prostate cancer risk: results from the selenium and Vitamin E cancer prevention trial. Cancer Epidemiol Biomarkers Prev. 2014;23(8):1494-504.

46. Eichholzer M, Steinbrecher A, Kaaks R, Teucher B, Linseisen J, Rohrmann S. Effects of selenium status, dietary glucosinolate intake and serum glutathione S-transferase alpha activity on the risk of benign prostatic hyperplasia. BJU Int. 2012;110(11 Pt C):E879-85.

47. Zachara BA, Szewczyk-Golec K, Tyloch J, Wolski Z, Szylberg T, Stepien S, Kwiatkowski S, Bloch-Boguslawska E, Wasowicz W. Blood and tissue selenium concentrations and glutathione peroxidase activities in patients with prostate cancer and benign prostate hyperplasia. Neoplasma. 2005;52(3):248-54.

48. Freedland SJ, Carducci M, Kroeger N, Partin A, Rao JY, Jin Y, Kerkoutian S, Wu H, Li Y, Creel P, et al. A double-blind, randomized, neoadjuvant study of the tissue effects of POMx pills in men with prostate cancer before radical prostatectomy. Cancer Prev Res (Phila). 2013:6(10):1120-7.

49. Bostwick DG, Qian J. High-grade prostatic intraepithelial neoplasia. Mod Pathol. 2004;17(3):360-79.

50. Malignant tumor of prostate: Prostate cancer. National Center for Biotechnology Information (NCBI) http://www.ncbi.n/m.nih.gov/gtr/ conditions/C0376358/. Accessed 04/26/16.

51. Feldman BJ, Feldman D. The development of androgen-independent prostate cancer. Nat Rev Cancer. 2001;1(1):34-45.

52. Yang G, Truong LD, Wheeler TM, Thompson TC. Caveolin-1 expression in clinically confined human prostate cancer: a novel prognostic marker. Cancer Res. 1999;59(22):5719-23.

53. Ziaran S, Varchulova NZ, Bohmer D, Danisovic L. Biomarkers for determination prostate cancer: implication for diagnosis and prognosis. Neoplasma. 2015:62(5):683-91.

54. Gurunadha Rao Tunuguntla HS, Evans CP. Management of prostatitis. Prostate Cancer Prostatic Dis. 2002;5(3):172-9.

55. Shoskes DA, Berger R, Elmi A, Landis JR, Propert KJ, Zeitlin S. Muscle tenderness in men with chronic prostatitis/chronic pelvic pain syndrome: the chronic prostatitis cohort study. J Urol. 2008;179(2):556-60.

56. Krieger JN, Nyberg Jr L, Nickel JC. NIH consensus definition and classification of prostatitis. JAMA. 1999;282(3):236-7.

57. Litwin MS, McNaughton-Collins M, Fowler Jr FJ, Nickel JC, Calhoun EA Pontari MA, Alexander RB, Farrar JT, O'Leary MP. The National Institutes of Health chronic prostatitis symptom index: development and validation of a new outcome measure. Chronic Prostatitis Collaborative Research Network. J Urol. 1999;162(2):369-75.

58. Sharp VJ, Takacs EB, Powell CR. Prostatitis: diagnosis and treatment. Am Fam Physician. 2010;82(4):397-406.

59. Dotan $Y$, Lichtenberg D, Pinchuk I. Lipid peroxidation cannot be used as a universal criterion of oxidative stress. Prog Lipid Res. 2004;43(3):200-27.

60. Taheri MG, Hosseini-Zijoud SM, Heidary ST, Ghasemi H, Ranjbar A. Attenuation of cisplathin-induced toxic oxidative stress by propofol. Anesth Pain Med. 2014;4(4):e14221.

61. Milne GL, Yin H, Brooks JD, Sanchez S, Jackson RL, Morrow JD. Quantification of F2-isoprostanes in biological fluids and tissues as a measure of oxidant stress. Methods Enzymol. 2007;433:113-26. 
62. Kullisaar T, Turk S, Punab M, Mandar R. Oxidative stress-cause or consequence of male genital tract disorders? Prostate. 2012;72(9):977-83.

63. Ronnau CG, Verhaegh GW, Luna-Velez MV, Schalken JA. Noncoding RNAs as novel biomarkers in prostate cancer. Biomed Res Int. 2014;2014:591703.

64. Ali MI, Kondreddi HD, Veeresh B. Protective effect of 2-hydroxy-4-methoxy benzoic acid on testosterone induced benign prostatic hyperplasia in Wister rats. Eur J Pharmacol. 2013;698(1-3):397-403.

65. Alcaraz A, Hammerer P, Tubaro A, Schroder FH, Castro R. Is there evidence of a relationship between benign prostatic hyperplasia and prostate cancer? Findings of a literature review. Eur Urol. 2009;55(4):864-73.

66. Szewczyk-Golec K, Tyloch J, Czuczejko J. Antioxidant defense system in prostate adenocarcinoma and benign prostate hyperplasia of elderly patients. Neoplasma. 2015;62(1):119-23.

67. Strand DW, Jiang M, Murphy TA, Yi Y, Konvinse KC, Franco OE, Wang Y, Young JD, Hayward SW. PPARgamma isoforms differentially regulate metabolic networks to mediate mouse prostatic epithelial differentiation. Cell Death Dis. 2012:3:e361.

68. Figg WD, Thompson IM. Effect of 5alpha-reductase inhibitor use on mortality from prostate cancer. JAMA Oncol. 2015;1(3):321-2.

69. Hamilton MP, Rajapakshe Kl, Bader DA, Cerne JZ, Smith EA, Coarfa C, Hartig SM, McGuire SE. The landscape of microRNA targeting in prostate cancer defined by AGO-PAR-CLIP. Neoplasia. 2016;18(6):356-70.

70. American Cancer Society. Cancer Facts \& Figures 2013. Atlanta: American Cancer Society; 2013. http://www.cancer.org/research/cancerfactsfigures/ cancerfactsfigures/cancer-facts-figures.

71. Desai N, Sabanegh Jr E, Kim T, Agarwal A. Free radical theory of aging: implications in male infertility. Urology. 2010;75(1):14-9.

72. Paschos A, Pandya R, Duivenvoorden WC, Pinthus JH. Oxidative stress in prostate cancer: changing research concepts towards a novel paradigm for prevention and therapeutics. Prostate Cancer Prostatic Dis. 2013;16(3):217-25.

73. Hanahan D, Weinberg RA. Hallmarks of cancer: the next generation. Cell. 2011;144(5):646-74.

74. Bolton EM, Tuzova AV, Walsh AL, Lynch T, Perry AS. Noncoding RNAs in prostate cancer: the long and the short of it. Clin Cancer Res. 2014;20(1):35-43.

75. Mouraviev V, Lee B, Patel V, Albala D, Johansen TE, Partin A, Ross A, Perera RJ. Clinical prospects of long noncoding RNAs as novel biomarkers and therapeutic targets in prostate cancer. Prostate Cancer Prostatic Dis. 2016;19(1):14-20.

76. Malik B, Feng FY. Long noncoding RNAs in prostate cancer: overview and clinical implications. Asian J Androl. 2016;18(4):568-74.

77. Velonas VM, Woo HH, dos Remedios CG, Assinder SJ. Current status of biomarkers for prostate cancer. Int J Mol Sci. 2013;14(6):11034-60.

78. Lee RC, Feinbaum RL, Ambros V. The C. elegans heterochronic gene lin-4 encodes small RNAs with antisense complementarity to lin-14. Cell. 1993; 75(5):843-54.

79. Sapre N, Selth LA. Circulating microRNAs as biomarkers of prostate cancer: the state of play. Prostate Cancer. 2013;2013:539680.

80. Takahara K, li M, Inamoto T, Nakagawa T, Ibuki N, Yoshikawa Y, Tsujino T, Uchimoto T, Saito K, Takai T, et al. microRNA-145 mediates the inhibitory effect of adipose tissue-derived stromal cells on prostate cancer. Stem Cells Dev. 2016;25(17):1290-8.

81. Nguyen HC, Xie W, Yang M, Hsieh CL, Drouin S, Lee GS, Kantoff PW. Expression differences of circulating microRNAs in metastatic castration resistant prostate cancer and low-risk, localized prostate cancer. Prostate. 2013;73(4):346-54.

82. Seashols-Williams SJ, Budd W, Clark GC, Wu Q, Daniel R, Dragoescu E, Zehner ZE. miR-9 Acts as an OncomiR in Prostate Cancer through Multiple Pathways That Drive Tumour Progression and Metastasis. PLoS One. 2016;11(7):e0159601.

83. Liu R, Liu C, Zhang D, Liu B, Chen X, Rycaj K, Jeter C, Calhoun-Davis T, Li Y, Yang T, et al. miR-199a-3p targets stemness-related and mitogenic signaling pathways to suppress the expansion and tumorigenic capabilities of prostate cancer stem cells. Oncotarget. 2016. doi:10.18632/oncotarget.10652.

84. Mitchell PS, Parkin RK, Kroh EM, Fritz BR, Wyman SK, Pogosova-Agadjanyan EL, Peterson A, Noteboom J, O'Briant KC, Allen A, et al. Circulating microRNAs as stable blood-based markers for cancer detection. Proc Natl Acad Sci U S A. 2008;105(30):10513-8.

85. Mahn R, Heukamp LC, Rogenhofer S, von Ruecker A, Muller SC, Ellinger J. Urology. 2011;77(5):1265.e9-16.

86. Lodes MJ, Caraballo M, Suciu D, Munro S, Kumar A, Anderson B. Detection of cancer with serum miRNAs on an oligonucleotide microarray. PLoS One. 2009;4(7):e6229.
87. Zhang Y, Liu D, Chen X, Li J, Li L, Bian Z, Sun F, Lu J, Yin Y, Cai X, et al. Secreted monocytic miR-150 enhances targeted endothelial cell migration. Mol Cell. 2010;39(1):133-44.

88. Moltzahn F, Olshen AB, Baehner L, Peek A, Fong L, Stoppler H, Simko J, Hilton JF, Carroll P, Blelloch R. Microfluidic-based multiplex qRT-PCR identifies diagnostic and prognostic microRNA signatures in the sera of prostate cancer patients. Cancer Res. 2011;71(2):550-60.

89. Brase JC, Johannes M, Schlomm T, Falth M, Haese A, Steuber T, Beissbarth T, Kuner R, Sultmann $\mathrm{H}$. Circulating miRNAs are correlated with tumor progression in prostate cancer. Int J Cancer. 2011;128(3):608-16.

90. Gonzales JC, Fink LM, Goodman Jr OB, Symanowski JT, Vogelzang NJ, Ward DC. Comparison of circulating MicroRNA 141 to circulating tumor cells, lactate dehydrogenase, and prostate-specific antigen for determining treatment response in patients with metastatic prostate cancer. Clin Genitourin Cancer. 2011;9(1):39-45.

91. Zheng C, Yinghao S, Li J. MiR-221 expression affects invasion potential of human prostate carcinoma cell lines by targeting DVL2. Med Oncol. 2012; 29(2):815-22.

92. Yaman Agaoglu F, Kovancilar M, Dizdar Y, Darendeliler E, Holdenrieder S, Dalay N, Gezer U. Investigation of miR-21, miR-141, and miR-221 in blood circulation of patients with prostate cancer. Tumour Biol. 2011;32(3):583-8.

93. Selth LA, Townley S, Gillis JL, Ochnik AM, Murti K, Macfarlane RJ, Chi KN, Marshall VR, Tilley WD, Butler LM. Discovery of circulating microRNAs associated with human prostate cancer using a mouse model of disease. Int J Cancer. 2012;131(3):652-61.

94. Bryant RJ, Pawlowski T, Catto JW, Marsden G, Vessella RL, Rhees B, Kuslich C, Visakorpi T, Hamdy FC. Changes in circulating microRNA levels associated with prostate cancer. Br J Cancer. 2012;106(4):768-74.

95. Chen ZH, Zhang GL, Li HR, Luo JD, Li ZX, Chen GM, Yang J. A panel of five circulating microRNAs as potential biomarkers for prostate cancer. Prostate. 2012;72(13):1443-52.

96. Shen J, Hruby GW, McKiernan JM, Gurvich I, Lipsky MJ, Benson MC, Santella RM. Dysregulation of circulating microRNAs and prediction of aggressive prostate cancer. Prostate. 2012;72(13):1469-77.

97. Sanders I, Holdenrieder S, Walgenbach-Brunagel G, von Ruecker A, Kristiansen G, Muller SC, Ellinger J. Evaluation of reference genes for the analysis of serum miRNA in patients with prostate cancer, bladder cancer and renal cell carcinoma. Int J Urol. 2012;19(11):1017-25.

98. Nickel JC, Roehrborn CG, O'Leary MP, Bostwick DG, Somerville MC, Rittmaster RS. The relationship between prostate inflammation and lower urinary tract symptoms: examination of baseline data from the REDUCE trial. Eur Urol. 2008;54(6):1379-84

99. Sciarra A, Mariotti G, Salciccia S, Autran GA, Monti S, Toscano V, Di SF. Prostate growth and inflammation. J Steroid Biochem Mol Biol. 2008;108(3-5):254-60.

100. Tsujii M, DuBois RN. Alterations in cellular adhesion and apoptosis in epithelial cells overexpressing prostaglandin endoperoxide synthase 2. Cell. 1995:83(3):493-501.

101. Yoshida GJ. Metabolic reprogramming: the emerging concept and associated therapeutic strategies. J Exp Clin Cancer Res. 2015;34:111.

102. Udensi UK, Cohly HH, Graham-Evans BE, Ndebele K, Garcia-Reyero N, Nanduri B, Tchounwou PB, Isokpehi RD. Aberrantly expressed genes in $\mathrm{HaCaT}$ keratinocytes chronically exposed to arsenic trioxide. Biomarker Insights. 2011;6:7-16.

103. Nwosu V, Carpten J, Trent JM, Sheridan R. Heterogeneity of genetic alterations in prostate cancer: evidence of the complex nature of the disease. Hum Mol Genet. 2001;10(20):2313-8.

104. Chu C, Qu K, Zhong FL, Artandi SE, Chang HY. Genomic maps of long noncoding RNA occupancy reveal principles of RNA-chromatin interactions. Mol Cell. 2011:44(4):667-78.

105. Zhao J, Ohsumi TK, Kung JT, Ogawa Y, Grau DJ, Sarma K, Song JJ, Kingston RE, Borowsky M, Lee JT. Genome-wide identification of polycombassociated RNAs by RIP-seq. Mol Cell. 2010;40(6):939-53.

106. Karayi MK, Markham AF. Molecular biology of prostate cancer. Prostate Cancer Prostatic Dis. 2004;7(1):6-20.

107. Gronberg H, Smith J, Emanuelsson M, Jonsson BA, Bergh A, Carpten J, Isaacs W, Xu J, Meyers D, Trent J, et al. In Swedish families with hereditary prostate cancer, linkage to the HPC1 locus on chromosome 1q24-25 is restricted to families with early-onset prostate cancer. Am J Hum Genet. 1999;65(1):134-40.

108. Xu J, Meyers D, Freije D, Isaacs S, Wiley K, Nusskern D, Ewing C, Wilkens E, Bujnovszky P, Bova GS, et al. Evidence for a prostate cancer susceptibility locus on the X chromosome. Nat Genet. 1998;20(2):175-9. 
109. Eeles RA, Kote-Jarai Z, Giles GG, Olama AA, Guy M, Jugurnauth SK, Mulholland S, Leongamornlert DA, Edwards SM, Morrison J, et al. Multiple newly identified loci associated with prostate cancer susceptibility. Nat Genet. 2008;40(3):316-21.

110. Thomas G, Jacobs KB, Yeager M, Kraft P, Wacholder S, Orr N, Yu K, Chatterjee N, Welch R, Hutchinson A, et al. Multiple loci identified in a genome-wide association study of prostate cancer. Nat Genet. 2008; 40(3):310-5

111. Song LN, Bowen C, Gelmann EP. Structural and functional interactions of the prostate cancer suppressor protein NKX3.1 with topoisomerase I. Biochem J. 2013:453(1):125-36.

112. Ntais C, Polycarpou A, loannidis JP. Association of GSTM1, GSTT1, and GSTP1 gene polymorphisms with the risk of prostate cancer: a meta-analysis. Cancer Epidemiol Biomarkers Prev. 2005;14(1):176-81.

113. Prostate Cancer Molecular Biology, http://www.cancerindex.org/. Accessed 15 Apr 2016.

114. Bettin A, Reyes I, Reyes N. Gene expression profiling of prostate cancerassociated genes identifies fibromodulin as potential novel biomarker for prostate cancer. Int J Biol Markers. 2015. doi:10.5301/jbm.5000184.

115. Lee HA, Park I, Byun HJ, Jeoung D, Kim YM, Lee H. Metastasis suppressor KAl1/CD82 attenuates the matrix adhesion of human prostate cancer cells by suppressing fibronectin expression and beta1 integrin activation. Cell Physiol Biochem. 2011;27(5):575-86.

116. Sjoblom L, Saramaki O, Annala M, Leinonen K, Nattinen J, Tolonen T, Wahlfors T, Nykter M, Bova GS, Schleutker J, et al. Microseminoprotein-Beta Expression in Different Stages of Prostate Cancer. PLoSOne. 2016;11(3): e0150241.

117. PLOS ONE Staff. Correction: Microseminoprotein-Beta Expression in Different Stages of Prostate Cancer. PLoS One. 2016;11(4):e0153732.

118. Ikeda M, Hirabayashi S, Fujiwara N, Mori H, Kawata A, lida J, Bao Y, Sato Y, lida T, Sugimura H, et al. Ras-association domain family protein 6 induces apoptosis via both caspase-dependent and caspase-independent pathways. Exp Cell Res. 2007;313(7):1484-95.

119. Muhammad LA, Saad F. The role of clusterin in prostate cancer: treatment resistance and potential as a therapeutic target. Expert Rev Anticancer Ther. 2015;15(9):1049-61.

120. Fujimoto $\mathrm{N}$, Kanno J. Increase in prostate stem cell antigen expression in prostatic hyperplasia induced by testosterone and 17beta-estradiol in C57BL mice. J Steroid Biochem Mol Biol. 2016;158:56-62.

121. Lokody IB, Francis JC, Gardiner JR, Erler JT, Swain A. Pten Regulates Epithelial Cytodifferentiation during Prostate Development. PLoS One. 2015;10(6):e0129470.

122. Alvarez-Cubero MJ, Martinez-Gonzalez LJ, Saiz M, Carmona-Saez P, Alvarez JC, Pascual-Geler M, Lorente JA, Cozar JM. Prognostic role of genetic biomarkers in clinical progression of prostate cancer. Exp Mol Med. 2015;47:e176.

123. Izmirli M, Arikan B, Bayazit Y, Alptekin D. Associations of polymorphisms in HPC2/ELAC2 and SRD5A2 genes with benign prostate hyperplasia in Turkish men. Asian Pac J Cancer Prev. 2011;12(3):731-3.

124. Cao DL, Ye DW, Dai B, Zhang HL, Shen YJ, Zhu Y, Zhu YP, Shi GH, Ma CG, Xiao WJ, et al. Association of glutathione S-transferase T1 and M1 polymorphisms with prostate cancer susceptibility in populations of Asian descent: a meta-analysis. Oncotarget. 2015;6(34):35843-50.

125. Zabaiou N, Mabed D, Lobaccaro JM, Lahouel M. Oxidative stress in benign prostate hyperplasia. Andrologia. 2015. doi:10.1111/and.12420.

126. Mak P, Li J, Samanta S, Mercurio AM. ERbeta regulation of NF-kB activation in prostate cancer is mediated by HIF-1. Oncotarget. 2015; 6(37):40247-54

127. Poniah P, Mohamed Z, Apalasamy YD, Mohd ZS, Kuppusamy S, Razack AH. Genetic polymorphisms in the androgen metabolism pathway and risk of prostate cancer in low incidence Malaysian ethnic groups. Int J Clin Exp Med. 2015;8(10):19232-40.

128. Millar DS, Ow KK, Paul CL, Russell PJ, Molloy PL, Clark SJ. Detailed methylation analysis of the glutathione S-transferase pi (GSTP1) gene in prostate cancer. Oncogene. 1999:18(6):1313-24.

129. Kanwal R, Pandey M, Bhaskaran N, Maclennan GT, Fu P, Ponsky LE, Gupta S. Protection against oxidative DNA damage and stress in human prostate by glutathione S-transferase P1. Mol Carcinog. 2014;53(1):8-18.

130. Hayes JD, Pulford DJ. The glutathione S-transferase supergene family: regulation of GST and the contribution of the isoenzymes to cancer chemoprotection and drug resistance. Crit Rev Biochem Mol Biol. 1995: 30(6):445-600
131. Ryberg D, Skaug V, Hewer A, Phillips DH, Harries LW, Wolf CR, Ogreid D, Ulvik A, Vu P, Haugen A. Genotypes of glutathione transferase M1 and P1 and their significance for lung DNA adduct levels and cancer risk. Carcinogenesis. 1997;18(7):1285-9.

132. Lee WH, Morton RA, Epstein Jl, Brooks JD, Campbell PA, Bova GS, Hsieh WS, Isaacs WB, Nelson WG. Cytidine methylation of regulatory sequences near the pi-class glutathione S-transferase gene accompanies human prostatic carcinogenesis. Proc Natl Acad Sci U S A. 1994;91(24): 11733-7.

133. Cookson MS, Reuter VE, Linkov I, Fair WR. Glutathione S-transferase PI (GSTpi) class expression by immunohistochemistry in benign and malignant prostate tissue. J Urol. 1997;157(2):673-6.

134. Hamid AR, Umbas $R$, Mochtar CA. Recent role of inflammation in prostate diseases: chemoprevention development opportunity. Acta Med Indones. 2011:43(1):59-65.

135. Labanca E, De LP, Gueron G, Paez A, Moiola CP, Massillo C, Porretti J, Giudice J, Zalazar F, Navone N, et al. Association of HO-1 and BRCA1 is critical for the maintenance of cellular homeostasis in prostate cancer. Mol Cancer Res. 2015:13:1455-64.

136. Jones KJ, Chetram MA, Bethea DA, Bryant LK, Odero-Marah V, Hinton CV. Cysteine (C)-X-C Receptor 4 Regulates NADPH Oxidase-2 During Oxidative Stress in Prostate Cancer Cells. Cancer Microenviron. 2013 [Epub ahead of print].

137. Antognelli C, Mezzasoma L, Mearini E, Talesa VN. Glyoxalase 1-419C>A variant is associated with oxidative stress: implications in prostate cancer progression. PLoS One. 2013;8(9):e74014.

138. Zeng Y, Gao D, Kim JJ, Shiraishi T, Terada N, Kakehi Y, Kong C, Getzenberg $\mathrm{RH}$, Kulkarni P. Prostate-associated gene 4 (PAGE4) protects cells against stress by elevating p21 and suppressing reactive oxygen species production. Am J Clin Exp Urol. 2013:1(1):39-52.

139. Wong N, Yan J, Ojo D, De MJ, Cutz JC, Tang D. Changes in PKM2 associate with prostate cancer progression. Cancer Invest. 2014;32(7): 330-8.

140. Tsouko E, Khan AS, White MA, Han JJ, Shi Y, Merchant FA, Sharpe MA, Xin L, Frigo DE. Regulation of the pentose phosphate pathway by an androgen receptor-mTOR-mediated mechanism and its role in prostate cancer cell growth. Oncogenesis. 2014;3:e103.

141. Griffiths K, Prezioso D, Turkes A, Denis LJ. The prevention of prostate cancer. Recent Results Cancer Res. 2007;175:33-63.

142. Lewinska A, Siwak J, Rzeszutek I, Wnuk M. Diosmin induces genotoxicity and apoptosis in DU145 prostate cancer cell line. Toxicol In Vitro. 2015; 29(3):417-25

143. Denis LJ, Griffiths K. Endocrine treatment in prostate cancer. Semin Surg Oncol. 2000;18(1):52-74.

144. Tammela TL. Endocrine prevention and treatment of prostate cancer. Mol Cell Endocrinol. 2012;360(1-2):59-67.

145. Rozanov D, Cheltsov A, Sergienko E, Vasile S, Golubkov V, Aleshin AE, Levin T, Traer E, Hann B, Freimuth J, et al. TRAlL-Based High Throughput Screening Reveals a Link between TRAIL-Mediated Apoptosis and Glutathione Reductase, a Key Component of Oxidative Stress Response. PLOS One 2015:10(6):e0129566.

146. Shiota M, Yokomizo A, Naito S. [The development of therapeutics targeting oxidative stress in prostate cancer]. Nihon Rinsho. 2014:72(12):2131-5.

147. Guo J, Wang M, Liu X. MicroRNA-195 suppresses tumor cell proliferation and metastasis by directly targeting BCOX1 in prostate carcinoma. J Exp Clin Cancer Res. 2015;34:91.

148. Azzouni F, Godoy A, Li Y, Mohler J. The 5 alpha-reductase isozyme family: a review of basic biology and their role in human diseases. Adv Urol. 2012; 2012:530121.

149. Clark RV, Hermann DJ, Cunningham GR, Wilson TH, Morrill BB, Hobbs S. Marked suppression of dihydrotestosterone in men with benign prostatic hyperplasia by dutasteride, a dual 5alpha-reductase inhibitor. J Clin Endocrinol Metab. 2004;89(5):2179-84.

150. Naber KG. Antibiotic treatment of chronic bacterial prostatitis. In: Nickel JC, editor. Textbook of Prostatitis. Oxford: Isis Medical Media; 1999. p. 285-92.

151. Gupta SC, Hevia D, Patchva S, Park B, Koh W, Aggarwal BB. Upsides and downsides of reactive oxygen species for cancer: the roles of reactive oxygen species in tumorigenesis, prevention, and therapy. Antioxid Redox Signal. 2012;16(11):1295-322

152. Gradini R, Realacci M, Ginepri A, Naso G, Santangelo C, Cela O, Sale P, Berardi A, Petrangeli E, Gallucci M, et al. Nitric oxide synthases in normal 
and benign hyperplastic human prostate: immunohistochemistry and molecular biology. J Pathol. 1999;189(2):224-9.

153. Hu M, Dillard C. Plasma SH and GSH measurement. Methods Enzymol. 1994; 233(385):87.

154. Moore K, Roberts $\sqcup$. Measurement of lipid peroxidation. Free Radic Res. 1998;28(6):659-71.

155. Grune T. Protein Oxidation Products as Biomarkers. Free Radic Biol Med. 2014;75 Suppl 1:S7.

156. Fields DA, Goran MI, McCrory MA. Body-composition assessment via airdisplacement plethysmography in adults and children: a review. Am J Clin Nutr. 2002;75(3):453-67.

Submit your next manuscript to BioMed Central and we will help you at every step:

- We accept pre-submission inquiries

- Our selector tool helps you to find the most relevant journal

- We provide round the clock customer support

- Convenient online submission

- Thorough peer review

- Inclusion in PubMed and all major indexing services

- Maximum visibility for your research

Submit your manuscript at www.biomedcentral.com/submit 